This manuscript was initially submitted to COASTAL ENGINEERING on $4^{\text {th }}$ June 2020 . The article was rejected by that journal on $7^{\text {th }}$ Aug 2020. We are revising the manuscript according to reviewer recommendations and will submit to a different journal.

If accepted on resubmission, the final version of the manuscript will be available via the 'Peerreviewed Publication DOI' on the right-hand side of this webpage. Please free to contact the corresponding author with any feedback:

R. Jak McCarroll (jak.mccarroll@plymouth.ac.uk) 


\title{
A novel rules-based shoreface translation model for predicting future coastal change: ShoreTrans
}

R. Jak McCarroll ${ }^{1}$, Gerd Masselink ${ }^{1}$, Nieves G. Valiente ${ }^{2}$, Timothy Scott ${ }^{1}$, Mark Wiggins ${ }^{1}$, Josie-Alice Kirby ${ }^{1}$ and Mark Davidson ${ }^{1}$.

\author{
${ }^{1}$ School of Biological and Marine Sciences, Plymouth University, Drake Circus, PL4 8AA, Plymouth, UK \\ ${ }^{2}$ Met Office, Fitzroy Road, EX1 3PB, Exeter, UK \\ Corresponding author: R. Jak McCarroll (jak.mccarroll@plymouth.ac.uk)
}

\section{Highlights}

- ShoreTrans predicts trend change and variability on real-world, complex coastlines

- Incorporates dunes, barriers, seawalls, rocks/cliffs and open sediment budgets

- Shoreline forcing controls vary widely within and between sites for 1-m SLR over 100-years

- Up to $\pm 50 \%$ difference in translation relative to Bruun-rule, depending on profile morphology

- Severe reduction in beach width predicted for seawall backed profiles

\section{Keywords}

Sea-level rise; multi-decadal coastal evolution; shoreline modelling; Bruun-rule. 


\begin{abstract}
Predicting change to global shorelines presents an increasing challenge as sea-level rise (SLR) accelerates. Many shoreline prediction models use variations of the 'Bruun-rule', failing to account for relevant processes and morphologic complexity. To address this, we introduce a simple rules-based model (ShoreTrans) designed for complex, real-world profiles that predicts change across a wide variety of sand, gravel, rock and engineered coasts at a temporal scale of 10-100 years, accounting for shoreline trends as well as variability. The model translates 2D cross-sections of the shoreface, using the surveyed profile, then integrates these cross-shore shoreface changes across multiple alongshore profiles to assess a simplified 3D sediment budget. Uncertainty is accounted for using a probabilistic distribution for model inputs and Monte Carlo simulations. The model accounts for: (1) dune encroachment/accretion; (2) barrier rollback; (3) non-erodible layers; (4) seawalls; (5) lower shoreface transport; (6) cross-shore storm erosion; (7) alongshore rotation; and (8) other sources and sinks. We apply the model to two macrotidal UK embayments: Perranporth (sandy, dissipative, crossshore dominant transport) and Start Bay (gravel, reflective, bi-directional alongshore dominant), then use idealised models to investigate the relative importance of forcing controls on shoreline recession and beach width. For the dissipative sandy site, the primary modes of coastal change are predicted to be short-term storm erosion and SLR translation. By contrast, for the reflective gravel site, the primary mode is multi-decadal longshore sediment flux, while short-term alongshore rotation and SLR translation are secondary. Relative to the new model, the Bruun-rule under-predicts shoreline recession in front of cliffs, seawalls and for low barriers that rollback, and over-predicts where large erodible dunes are present. Beaches in front of seawalls and cliffs are predicted to shrink, such that narrow beaches ( $<50 \mathrm{~m}$ width) may disappear under 1-m SLR. ShoreTrans is easily transferable to many coastal environments and will provide a useful tool for coastal practitioners to make rapid estimates of future coastal change to complex shorelines.
\end{abstract}




\section{Introduction}

Coasts are amongst the most densely populated regions on the planet and predicting how coastlines will respond to accelerating sea-level rise (SLR) over coming decades is one of the primary challenges facing the field of coastal research. Sandy shores make up one-third of the world's coastlines and onequarter of these may be eroding under present low rates $(<5 \mathrm{~mm} / \mathrm{yr})$ of SLR $[1,2]$. Under accelerated rates of SLR, all global shorelines are likely to recede landward without significant nourishment [3], excepting in isolated cases with large positive sediment budgets or significant isostatic rebound. On natural, unmodified coastlines, with ample sediment availability, the shoreface will in most instances be translated upward and onshore (e.g., [4]), maintaining beach width. By contrast, on hardengineered or rocky coastlines, where seawalls or cliffs bound the back of the beach, or where infrastructure such as housing or roads restrict onshore translation, then projected SLR may lead to the disappearance beaches by the end of the century $[5,6]$. A gradual rise in SLR and associated coastal recession will also exacerbate the frequency and severity of extreme events such as coastal flooding [7], and the erosional and direct structural impacts of extreme storms [8].

Longer-term (decadal to centennial) changes to a coastal profile are a function of variations in the sediment budget $[3,9,10]$, combined with the amount and rate of SLR. At longer timescales (100's to 1,000 's years), shoreline changes are increasingly a function of the hinterland surface gradient [11]. We restrict our analysis to $\leq 100$ years, where sediment budget and SLR are the dominant controls.

Shoreline recession ( $R_{\text {total }}$, noting we take negative as onshore) is a function of the rate of SLR interacting with the changing profile shape, combined with cross-shore input, longshore input and other sources/sinks, which may include exchange with dunes, the back-barrier and estuaries, as well as profile nourishment or sediment extraction.

$$
R_{\text {total }}=f_{S L R}+f_{\text {cross-shore }}+f_{\text {longshore }}+f_{\{\text {sources,sinks }\}}
$$

The first term on the right can be described as the SLR function. The SLR function is most typically applied using the Bruun-rule, which acts to raise and shift the profile onshore and assumes all sediment transport is offshore. Taking $\Delta S$ as the change in sea-level, for a profile with width $\left(W_{*}\right)$ extending from the berm crest $(B)$ to the depth of closure $\left(Z_{D 1}\right.$; closure is further defined in Section 2.1), the standard Bruun-rule $[4,12,13]$ is

$$
R_{\text {Bruun }}=-\Delta S\left(\frac{W_{*}}{Z_{D 1}+\mathrm{B}}\right)
$$


Later iterations (e.g., $[14,15])$ demonstrated that the elevation of the dune toe or the crest of barrier $\left(Z_{C}\right.$, Fig. 1$)$ is more appropriate for realistic profiles, than using an idealised berm height $(B)$. For profiles with a low barrier where rollover is occurring, some degree of onshore transport will occur $[9,10]$, and therefore the standard Bruun-rule will underestimate recession magnitude. The Generalised Bruun-rule [16] can account for beaches with a back-barrier, with width $W_{\text {back }}$,

$$
R_{\text {Bruun,Gen }}=-\Delta S\left(\frac{W_{*}+W_{\text {back }}}{Z_{D 1}-Z_{\text {back }}}\right)
$$

where $Z_{\text {back }}$ is the depth of closure or base of beach sediment in the lagoon backing the barrier. The standard Bruun-rule (Eq. 2) is an end-member instance of the general rule, in which case $W_{\text {back }}=0$. Applying (2) and (3), recession rates will be lower for erodible dune-backed beaches (offshore transport) and higher for barriers that rollover (onshore transport). This can be shown along a continuum of profile shapes [10] and has been generalised to account for longer time periods, with varying underlying substrate morphology [11].

The Bruun approach represents only the SLR function. Any application should also include the additional terms in (1), including trends in cross- and alongshore transport, as well as other sources and sinks. Dean and Houston [3] applied the standard Bruun-rule to the West Florida coastline, then highlighted the importance of gradual onshore transport from below the depth of closure, forced by shoaling wave asymmetry. The rate of onshore transport in southwest Florida is estimated at 3 $\mathrm{m}^{3} / \mathrm{m} / \mathrm{yr}$, which for that coastline is insufficient to maintain shoreline position under projected SLR scenarios. Cowell et al. [17] estimated a typical rate of onshore transport for concave up sandy shorefaces with stable sea-level is $1 \mathrm{~m}^{3} / \mathrm{m} / \mathrm{yr}$, with higher values during Holocene SLR rise in Australia producing extensive progradational coastal plains in some areas.

Morphodynamic modelling of future coastlines comes in a variety of forms. Process-based (or physicsbased) models are now being shown to be capable of multi-decadal simulations [18] provided sophisticated down-scaling techniques are applied. Yet, such approaches are generally resource intensive, limiting their use to smaller spatial and temporal domains. 'Bottom-up' physics based morphodynamic models are also subject to significant error when run over longer periods due to presently unresolvable sediment transport processes (a form of epistemic uncertainty) which must be crudely parameterised [19].

Combined one-line 'cross-shore, longshore' (also known as 'hybrid' or 'reduced complexity') models which may or may not include SLR (e.g., $[7,19,20,21]$ ) offer a fast, convenient alternative that can be used to assess larger regions (100's km) at decadal-centennial timescales. The longshore transport 
A shoreface translation model for predicting future coastal change: ShoreTrans

component of these models is generally a pre-existing longshore transport equation (e.g., CERC). The cross-shore component is typically based on a shoreline equilibrium model (e.g., $[22,23])$. The SLR translation function, if present, may use the Bruun-rule, or be incorporated into the cross-shore model.

Another subset of SLR predictors can be described as simple, rules-based, translation models, which assume an equilibrium upper shoreface profile, that can adapt rapidly relative to SLR. These models parameterise key aspects of the geometry of the shoreface profile (e.g., profile width, base of active profile). The Shoreface Translation Model (STM) of Cowell et al. $[15,24]$ applies a given SLR and solves numerically to conserve volume, dealing with uncertainty. Another translation model [25], parameterises profile geometry and adds a simple cross-shore transport formulation to the lower shoreface, while Storms et al. [26] presented a process-based model capable of producing similar results at geological timescales. Profile translation models are extremely useful in providing a fast estimate of the future shoreline change envelope, potentially encompassing both trend changes and short-term variability. Of note, they can be used to test the impact of uncertainty by applying probability distributions to input variables in order to determine a probabilistic distribution of outcomes [10]. Two recent flume-based studies tested simple translation models against observed laboratory data $[27,28]$, determining that an effective technique for estimating SLR impacts on complex profiles was to algorithmically raise the existing profile, then iteratively shift it onshore until volume is conserved. This approach, applied to realistic barred profiles, will produce cross-shore variations in onshore/offshore transport, and therefore may produce different results to applying Eq. 2 directly. For wall-backed profiles [28], the profile is translated onshore as if the wall were not present, then the hypothetical erosion demand behind the wall is transferred to offshore of the wall, potentially reducing beach width.

The application of translation models has been fairly limited in determining SLR impacts. Recent examples of the translation approach include Kinsela et al. [29], who introduced a method for including short-term variability in a translation model, while Wainright et al. [30] showed the benefits of using both a translation model for long-term change and a joint-probabilistic storm erosion model for assessing short-term variability.

Here we present a novel shoreface translation model (ShoreTrans) based on the approach of $[27,28]$, using the original profile for translation, as opposed to the parameterisations of earlier approaches (e.g., $[11,15,25,31])$. This is a key difference as it removes the assumption of an idealised equilibrium profile. We expand this approach (Section 2) to account for various morphologic features and processes, including: seawalls, cliffs, dunes, bedrock substrate, dunes, short-term cross- and 
alongshore variability, as well as other sources and sinks. Using the original profile allows for the incorporation of high-resolution, site-specific features, such as irregularly shaped dunes, non-erodible substrate and structures. The model also incorporates probabilistic uncertainty, using previously established methods $[10,29]$. ShoreTrans is then applied to predict shoreface translation and sediment budgets at two long-term macrotidal monitoring sites in the UK: Perranporth Beach (Section 3) and Start Bay (Section 4). A conceptual approach demonstrating sensitivity in shoreline recession to varying inputs is introduced along with discussion in Section 5 , with conclusions presented in Section 6.

\section{Model Description}

Taking the approach of Cowell et al. [15], the translation model is governed by conservation of mass, or by volume, if density is assumed constant:

$$
\int_{a}^{b}\left(z_{t}-z_{t+1}\right) d x-\Delta V=0
$$

where $z$ is the bed elevation at time $(t), a$ is the onshore point of closure and $b$ is the offshore depth of closure. The main inputs to the model are displayed in Figure 1. The model requires at a minimum, a cross-shore profile $\left(x_{i}, z_{i}\right)$. Other optional inputs are outlined over the following sections.

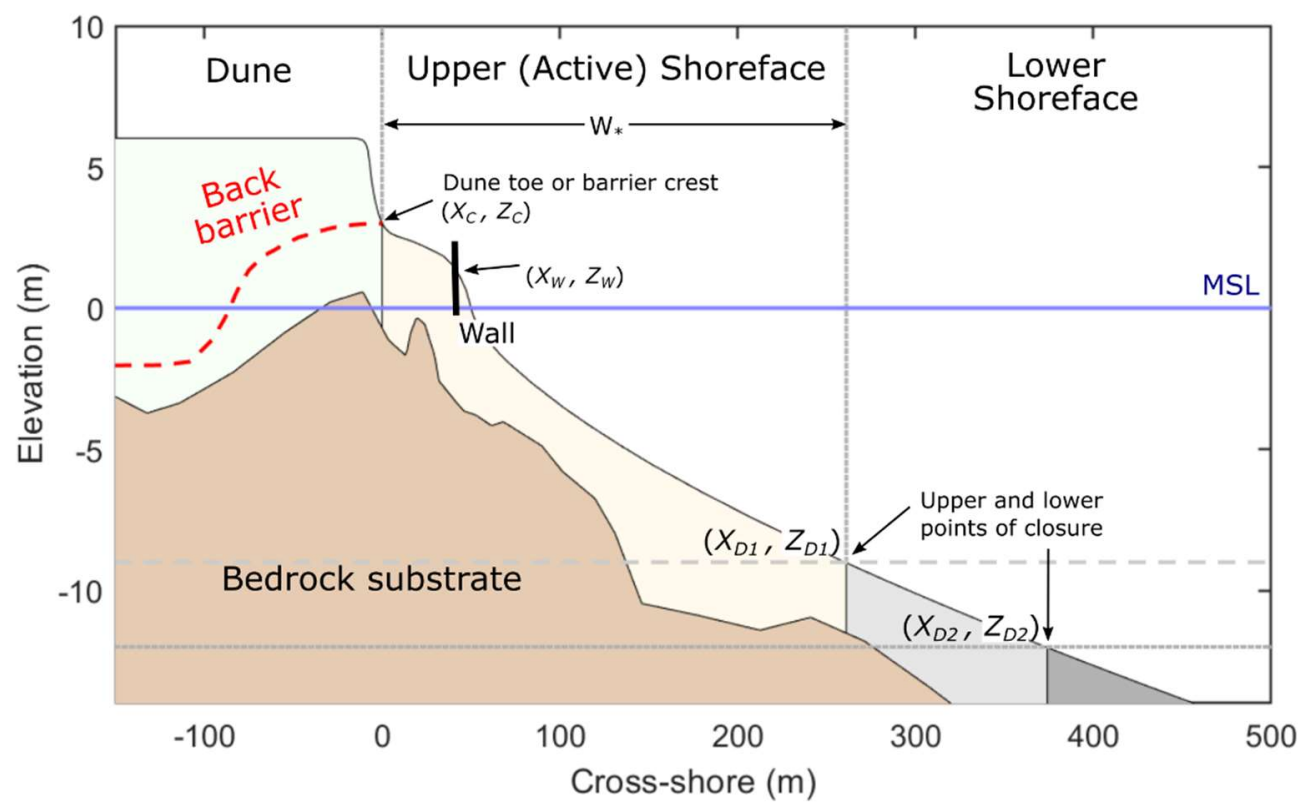

Figure 1. Components of the ShoreTrans model. 


\subsection{Profile translation}

The basic mechanism of the translation model is to shift the active profile (Fig. 2) up by the change in sea-level $(\Delta S)$ and iterate onshore until the net volume change is zero (as per [27]), such that

$$
z_{(x, t+1)}=z_{(x-\Delta X, t)}+\Delta S
$$

where $\Delta X$ is the cross-shore distance the profile is translated. The iterative process finds a solution to (Eq. 4) where the total volume change across the profile sums to zero. Smoothing is applied around the upper depth of closure $\left(Z_{D 1}\right)$, to avoid a step.

Depth of closure is variously described in the literature and is applied using widely varying, nonstandardised methods when predicting coastal change due to SLR. ShoreTrans uses two values, an 'upper' depth of closure $\left(Z_{D 1}\right)$ and 'lower' closure depth $\left(Z_{D 2}\right)$. As described above, the upper closure point defines the base of the active profile used for translation. The lower depth of closure is used in cases where sediment is gradually transported between the lower shoreface and the upper (active) shoreface (Section 2.4), as described by [3].

Common methods for determining depth of closure are introduced below, and further discussion of the uncertainty in selecting depth of closure is given in Sections 3.1 and 4.1. The first commonly used formula for closure estimates the maximum depth where detectable morphological change occurs over a given time frame, using the Nicholls et al. [32] adaption of the original formula of Hallermeier [33]

$$
D o C_{1}=2.28 H_{12, t}-68.5\left(\frac{H_{12, t}^{2}}{g T_{t}^{2}}\right)
$$

where $H_{12, t}^{2}$ is the significant wave height exceeded for $12 \mathrm{~h}$ per $t$ years and $T_{t}$ is the associated peak period. We suggest $D o C_{1}$ or a directly observed depth of morphological change should be used as the minimum (shallowest) bound when determining a probability distribution for the upper depth of closure $\left(Z_{D 1}\right)$. This is in line with [10], though many studies (e.g., [6]) use $D o C_{1}$ as the modal value for depth of closure when applying the Bruun-rule, which results in a shallower estimate of closure depth.

A second, deeper depth of closure [33] approximates to the point of no sediment motion [34] or the 'wave-base', and can be estimated using

$$
D o C_{2}=\left(\overline{H_{s, t}}-0.3 S D_{S}\right) \overline{T_{s, t}}\left(\frac{g}{5000 D_{50}}\right)^{0.5}
$$


where $\overline{H_{S, t}}$ is annual significant wave height, $S D_{S}$ is the wave height standard deviation, $\overline{T_{s, t}}$ is the time-averaged wave period and $D_{50}$ is the median grain size. We suggest that $D o C_{2}$ is a suitable modal value for $Z_{D 2}$, as per [10]. Note the we have used different variables for the closure depth observations/formulae $\left(D o C_{1}, D o C_{2}\right)$ as opposed to the model input elevations $\left(Z_{D 1}, Z_{D 2}\right)$ as these will not necessarily be identical.
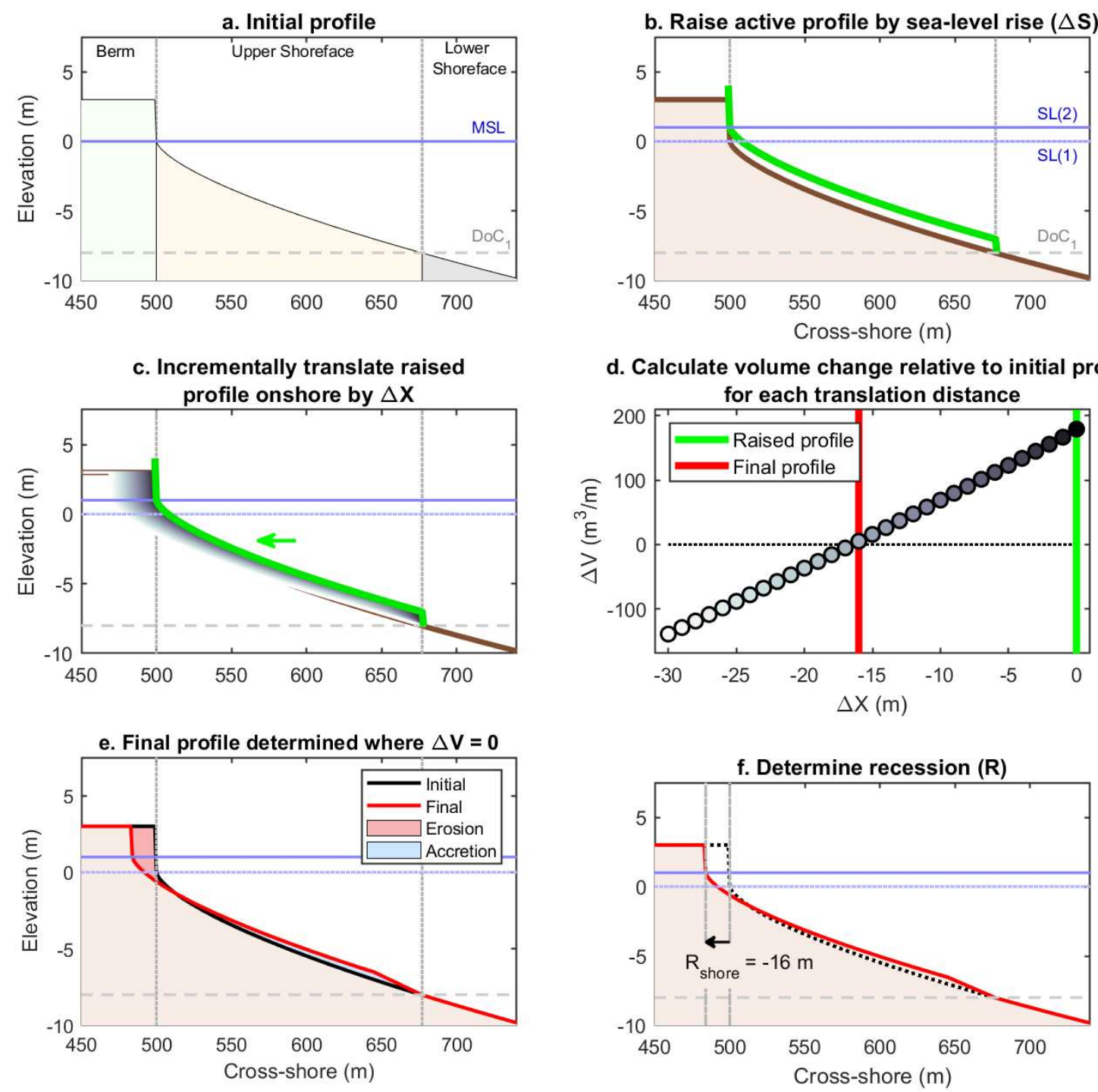

Figure 2. Active profile translation example using a Bruun-like profile, following the method of Atkinson et al., 2018. The shading in (c, d) are the envelope of translated profiles, from $0<\Delta X \leq 50 \mathrm{~m}$. 


\subsection{Profile translation involving seawall, cliffs and underlying non-erodible substrate}

Erosion demand on the upper profile under SLR is has been found to be similar for profiles with and without seawalls [28]. However, where a wall is present, the potential erosion onshore of the wall, were it not present, is transferred offshore to the area adjacent to the wall, concentrating erosion in the vicinity of the wall. The modelled translation process for a bermed profile with a seawall is shown in Figure 3a-c. Here, the profile is translated as if the wall were not present (as per Fig. 1), then the potential erosion ( $\left.\Delta V_{\text {wall demand }}\right)$ is calculated for the area onshore of the wall and below the elevation of the dune toe plus sea-level rise $\left(Z_{C}+\Delta S\right.$; Fig. $\left.3 \mathrm{~b}\right)$. The erosion demand is then distributed offshore of the wall (Fig. 3b-c). Given that [28] do not specify how the erosion demand should be redistributed offshore, the translation model applies the erosion as a triangular wedge that has maximum height at the wall, tapering to zero at user specified ratio of the cross-shore extent of the profile, with a default ratio of $1 / 3$ (see Limitations, Section 5). The wall is specified as a cross-shore location or the elevation of the surface profile at which the wall occurs. 'Walls' in the translation model may include hard-rock cliffs or cliffs buried under perched dunes, that become exposed by erosion.

Non-erodible surfaces may also be specified as a layer; typically, this will represent a bedrock substrate (Fig. 3, second column), but may also include sub-horizontal structures. Exposed rocks displace potential erosion (e.g., upper profile in Fig. 3e-f) and accretion (lower profile, Fig. 3e-f) during translation. However, in contrast to the seawall method (Fig. 3a-c), the displaced volume change is not redistributed to other parts of the profile, which is consistent with previous approaches [10,35]. The expected effect of an offshore reef is to partially fill additional accommodation space that is generated through SLR [29], thereby reducing the potential for shoreline recession.

\section{Maximum erosion limits for wall-backed profiles}

Persistent loss of sediment due to a negative sediment budget or large levels of SLR on a wall-backed profile may lead to severe erosion, and the disappearance of the sub-aerial beach. A manual limit can be set on how much erosion can occur by setting a minimum bed elevation value for the profile toe immediately offshore the wall. Once this limit is reached (e.g., mean low water springs), no further depletion of the profile will occur. If no wall-toe erosion limit is set, the profile will continue to erode until the entire profile reaches the upper depth of closure. The latter is likely to be unrealistic and we do not apply this approach in the subsequent applications. 

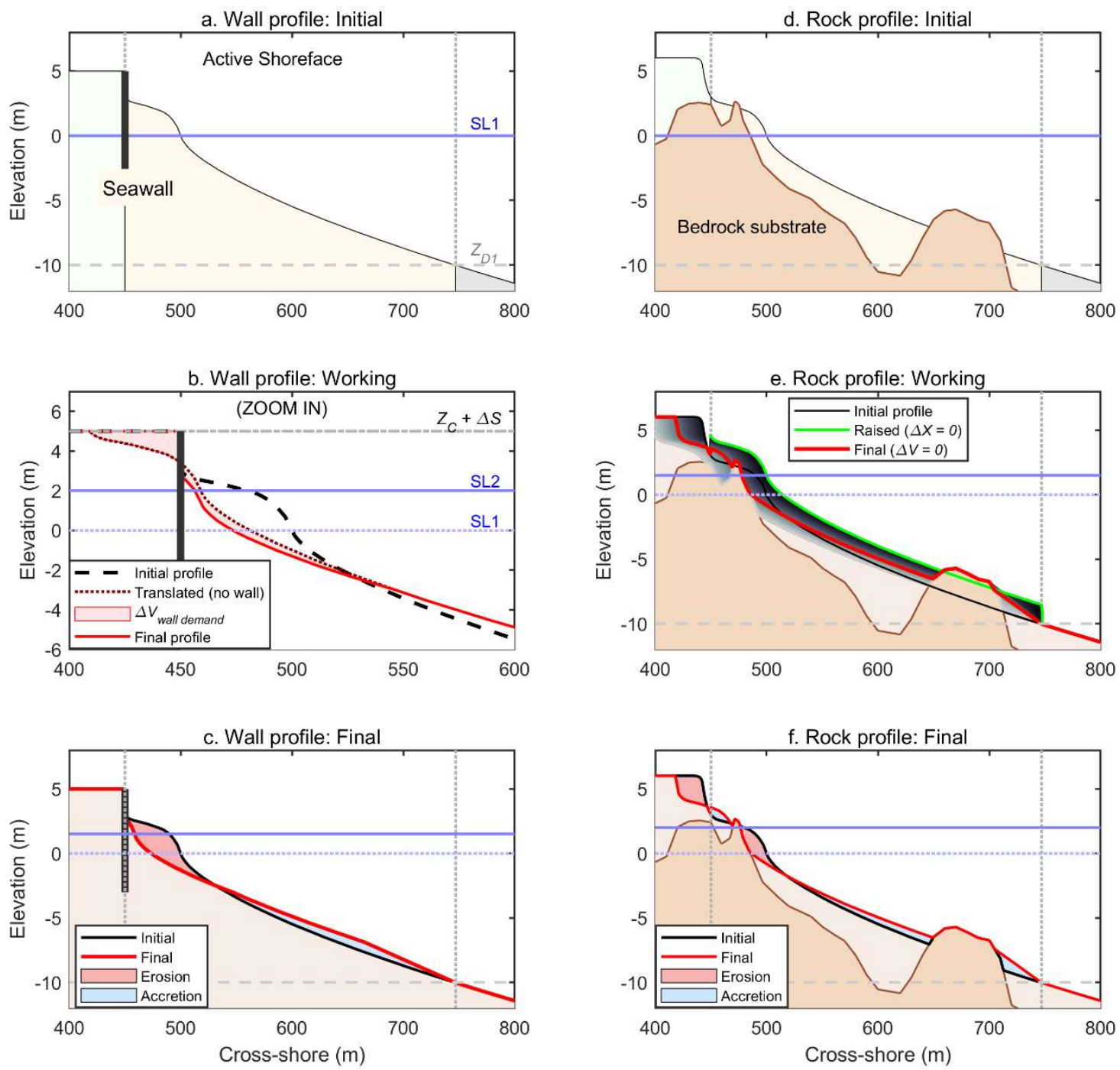

Figure 3. Profile translation method for walls and rocks. The greyscale shaded area in (e) represents the envelope of translation distances, $0<\Delta X \leq 50 \mathrm{~m}$. 


\subsection{Translation type: Rollover and encroachment}

Two end-member behaviours for translating barriers are 'rollover' and 'encroachment' [15]. Rollover is associated with low barriers, approximated with the generalised Bruun-rule (Eq. 3) and may involve only onshore transport [9] through the process of overwash. Encroachment typically occurs with mainland beaches backed by dunes and, if applying the standard Bruun-rule (Eq. 2), will involve only offshore transport. ShoreTrans employs a similar approach as the original STM, requiring the specification of the dune toe or barrier crest $\left(X_{C}, Z_{C}\right.$ in Fig. 1), depending on profile type, and selection of the translation type.

Three translation types are available in ShoreTrans: two end-member types, and an intermediate method, which are illustrated for translation of a low barrier backed by a shallow lagoon in Figure 4 . The first end-member, 'Type 1: Rollover and keep-up' translates the active profile, from the barrier crest $\left(X_{C}, Z_{C}\right.$ in Fig. 1), to the upper depth of closure $\left(X_{D 1}, Z_{D 1}\right)$, up and onshore, raising the height of the crest equal to the rise in sea-level. A uniform landward slope is applied behind the barrier (overwash slope, $\theta_{\text {back }}$ ), with a default value of $4^{\circ}$, but can be specified manually. The onshore point of closure occurs where the overwash slope intersects the initial profile. 'Type 2: Rollover and maintain' (Fig. 4c) permits overwash, but the barrier crest maintains its initial height. The second endmember, 'Type 3: Encroachment' restricts the height of the back barrier to its initial height and assumes erosion with no overwash (i.e., no onshore transport past the crest). For all three translation methods, volume is conserved by determining the profile iteration distance ( $\Delta X$, Fig. $2 \mathrm{~d})$ that satisfies Eq. 4.

This approach uses a number of simplifying assumptions: (i) a single angle is used to describe the shape of the back-barrier, which approximates more complex real-world back-barrier shapes (Fig. 5b); and (ii) the 'maintain initial height' option crops the barrier elevation at the initial crest level, resulting in a 'flat-top' (Fig. 5b) (see Limitations, Section 5).

Recession rates are highest for 'Type 1: Rollover and keep-up' (Fig. 5a), decreasing if the barrier rolls over but keeps its initial height (Fig. 5c), and is minimised for 'encroachment', where only offshore transport is permitted (Fig. $5 \mathrm{~d}$ ). Observations suggest all these behaviours may occur for natural barriers (e.g., see Section 4 on Start Bay). The type of translation behaviour a particular barrier will exhibit under future SLR is likely to be highly uncertain, noting that rollover transport is limited to infrequent high-energy events where overwash can occur $[36,37,38,39]$. ShoreTrans does not predict which of these behaviours will occur, but instead acts as a tool to investigate the likely recession rates under different encroachment/rollover scenarios. This approach allows for investigation of uncertainty by exploring a range of potential outcomes. 

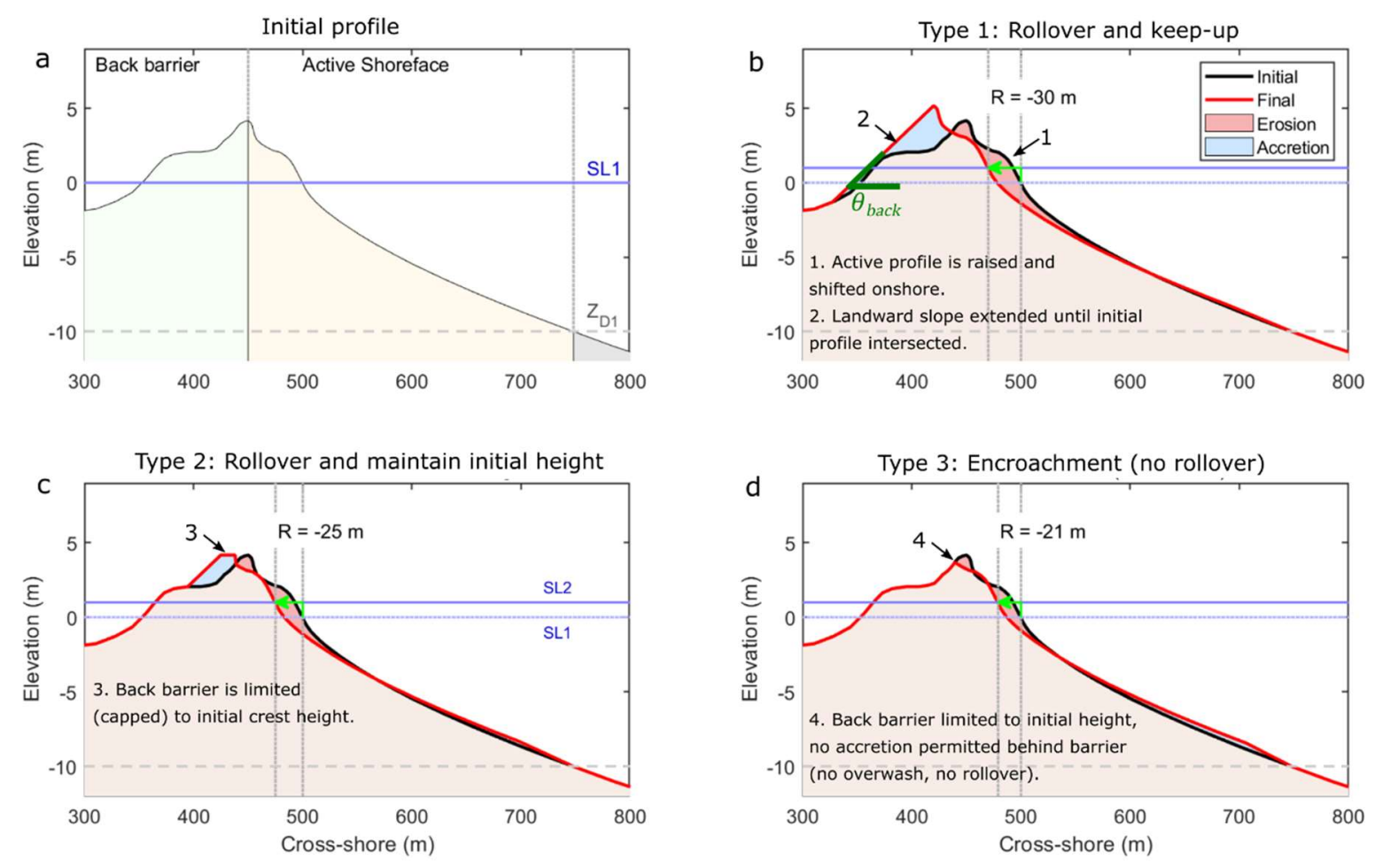

Figure 4. Low barriers (a) may be set to: (b) Type 1 - Rollover and keep-up; (c) Type 2 - Rollover and maintain; or (d) Type 3 - Encroachment, i.e., erode without rollover.

\section{Dune encroachment and vertical accretion}

Dune erosion occurs when employing 'Type 3: Encroachment' translation on a dune profile (Fig. 5) and is handled similarly to [29], with the toe raised and translated onshore. ShoreTrans allows for an input of 'aeolian dune accretion' applicable when using encroachment mode. Here, a user specified volume is added as a block of uniform height, prior to translation, over a specified distance onshore of the dune toe (Fig. 5a), with an equivalent volume subtracted uniformly from the active shoreface. Dune accretion rates can be determined from observation or by using typical values (e.g., [40]). This assumes that where aeolian vertical dune accretion is occurring, the dry beach is the short-term source of sediment, but over longer time periods (years to decades), the loss of sediment from the active shoreface will reach a new equilibrium such that the loss is uniformly distributed over the profile [40]. Dune slumping is handled by reclining the surface at the translated dune toe (Fig. 4b) by the angle $\theta_{\text {dune }}$, using a conservative angle for unconsolidated sediment of $30^{\circ}$ by default (as per [29]), which can be modified. Note the dune is slumped from the base of the 'sandwall', as opposed to the midpoint as in [29]. This allows buried cliff faces to become fully exposed, rather than being buried by slumped dunes. The onshore point of closure ( $a$ in Eq. 4 ) is the greatest onshore extent of profile 
modification, either through dune accretion or dune erosion. As with all modifications to the profile, volume is conserved in a later step by determining the profile iteration distance ( $\Delta X$, Fig. $2 \mathrm{~d})$ that satisfies Eq. 4.
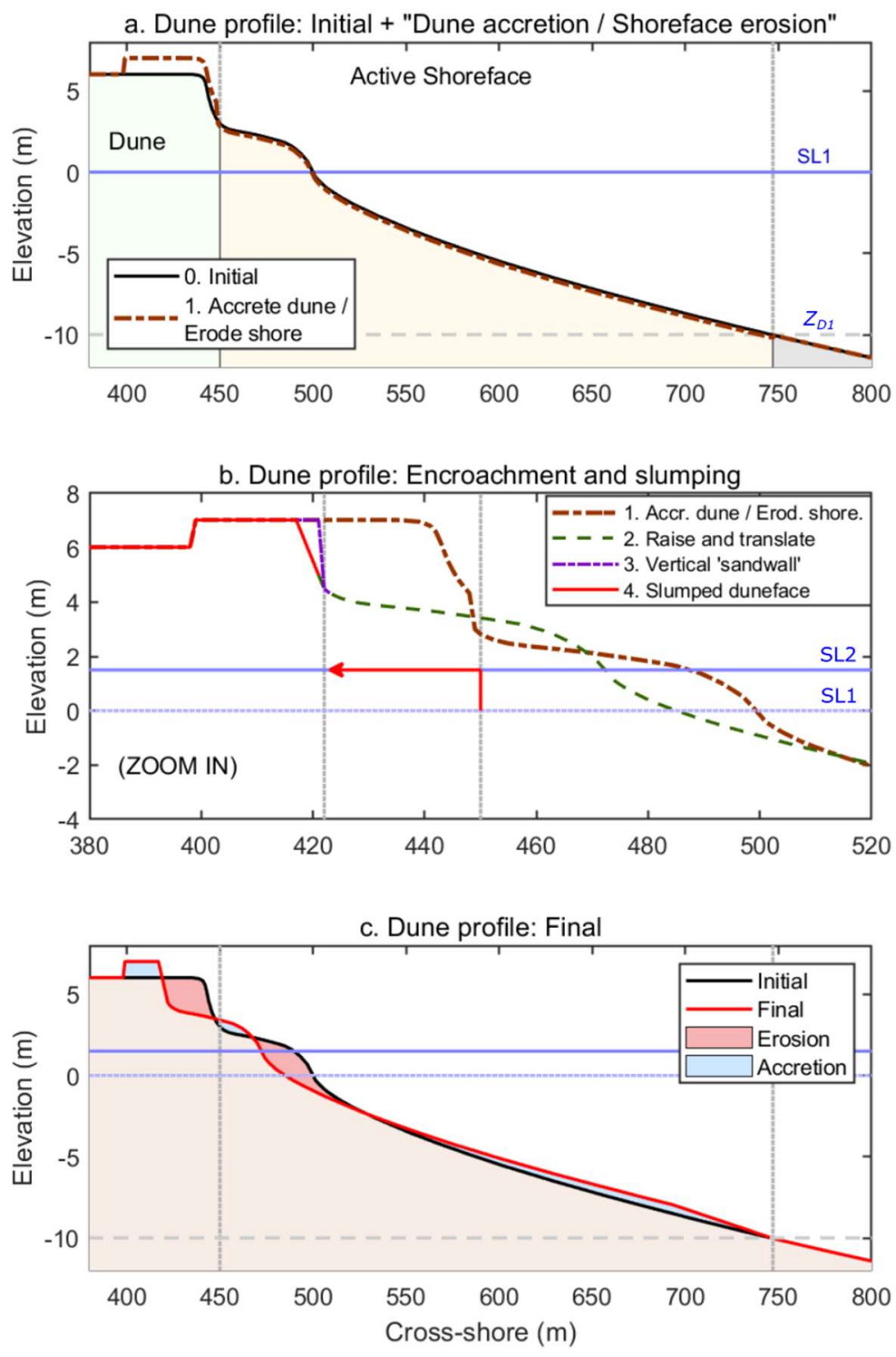

Figure 5. Dune erosion mechanics, including (a) the initial profile, with dune accretion / shoreface accretion applied, here $\Delta V_{\text {dune accretion }}=50 \mathrm{~m}^{3}$ applied from the dune toe $50 \mathrm{~m}$ onshore; (b) the profile is raised then translated onshore (red arrow indicates magnitudes), the resulting vertical 'sandwall' is slumped to a default angle of $\theta_{\text {dune }}=30^{\circ}$; (c) the final profile is determined where $\Delta V_{\text {total }}=0$. SL1 and SL2 are initial and final sea-level, $Z_{D l}$ is upper depth of closure. 
2.4. Cross-shore variability: Storm-demand and long-term sediment transfer with the lower shoreface

This section introduces methods to account for short-term variability of the upper (active) shoreface and long-term trends involving sediment transfer between the upper and lower shoreface (Fig. 1). All methods for cross-shore transport in this section conserve volume, as opposed to Section 2.5 which will cover longshore gains and losses to total profile volume.

Short-term variability in the cross-shore profile, due to the storm erosion-recovery cycle, is addressed first. The aim is to add the maximum variability to the long-term trend (including SLR translation) to predict the maximum instantaneous recession distance. This is a common approach in coastal change prediction models (e.g., $[6,29])$. Beaches impacted by storms experience a combination of high water levels, energetic waves and dominant bed-return flow. This results in offshore transport (erosion) from the sub-aerial beach and dunes, to the lower active profile. The berm is initially eroded and, if water levels and waves are sufficiently high, significant dune erosion may occur $[14,41,42]$.

We introduce two methods for applying maximum potential storm erosion (or 'storm demand'). Both methods require an estimate of total volume eroded $\left(\Delta V_{\text {storm }}\right)$ from above a specified elevation $\left(z_{\text {storm }}\right)$. Maximum storm demand can be determined by observation of the impact of a historic storm (e.g., Western Europe in 2013/14 [8]) and/or extreme value analysis of a time series of beach volume [29]. The primary aim for both methods is to simulate a specified volume loss at the top of the active profile to estimate shoreline and duneline recession. The reshaping of the lower part of the profile is applied in a simplified manner to balance volume but is not intended to realistically represent bar morphology (see Limitations, Section 5).

\section{Storm Demand Method 1: Bermed beaches with concave-up profiles}

The first method (Fig. 6a) for applying maximum storm erosion is based on the approach of [14], with influence from [29], generalised to allow for the translation of realistic profiles. We do not provide a method for short-term overwash of low barriers, treating that as a trend process (Section 2.3). For a given profile (Fig. 6a), the minimum inputs required are: the dune toe elevation $\left(Z_{c}\right), \mathrm{MSL}$ (typically > 0 as the storm demand is applied post-SLR), $Z_{D 1}, \Delta V_{\text {storm }}$ and $z_{\text {storm }}$. The algorithmic method for maximum storm-cut (Fig. 6a) is as follows:

1. A power-law profile (Dean [43]) is fitted from the dune-toe through the bottom-half the profile:

$$
z_{i}=-A x_{i}^{m}
$$


Where $z_{i}$ is the elevation for the cross-shore position, $x_{i}$ (offset to an origin at the dune toe), with initial estimates of $A=0.25$ (steepness) and $m=0.67$ (shape). Volume is added to the bottom-half of the profile as a half-wavelength Sine-curve to conserve total volume. The resulting curve simulates full erosion of the berm (Fig. 6a, Stage 1). If Stage 1 erosion > $\Delta V_{\text {storm }}$, no dune erosion occurs (skip step 2).

2. Dune erosion is accomplished through Bruun-type profile translation, as per [14], assuming the brief elevation in water-level during storms produces the same form of profile response as long-term SLR. Here, the previously described methods for profile translation are applied (Figs. 2-4), iterating $\Delta S$ to increase dune erosion until $\Delta V_{\text {berm }}$ (Stage 1) + $\Delta V_{\text {dune }}($ Stage 2$)=\Delta V_{\text {storm }}$.
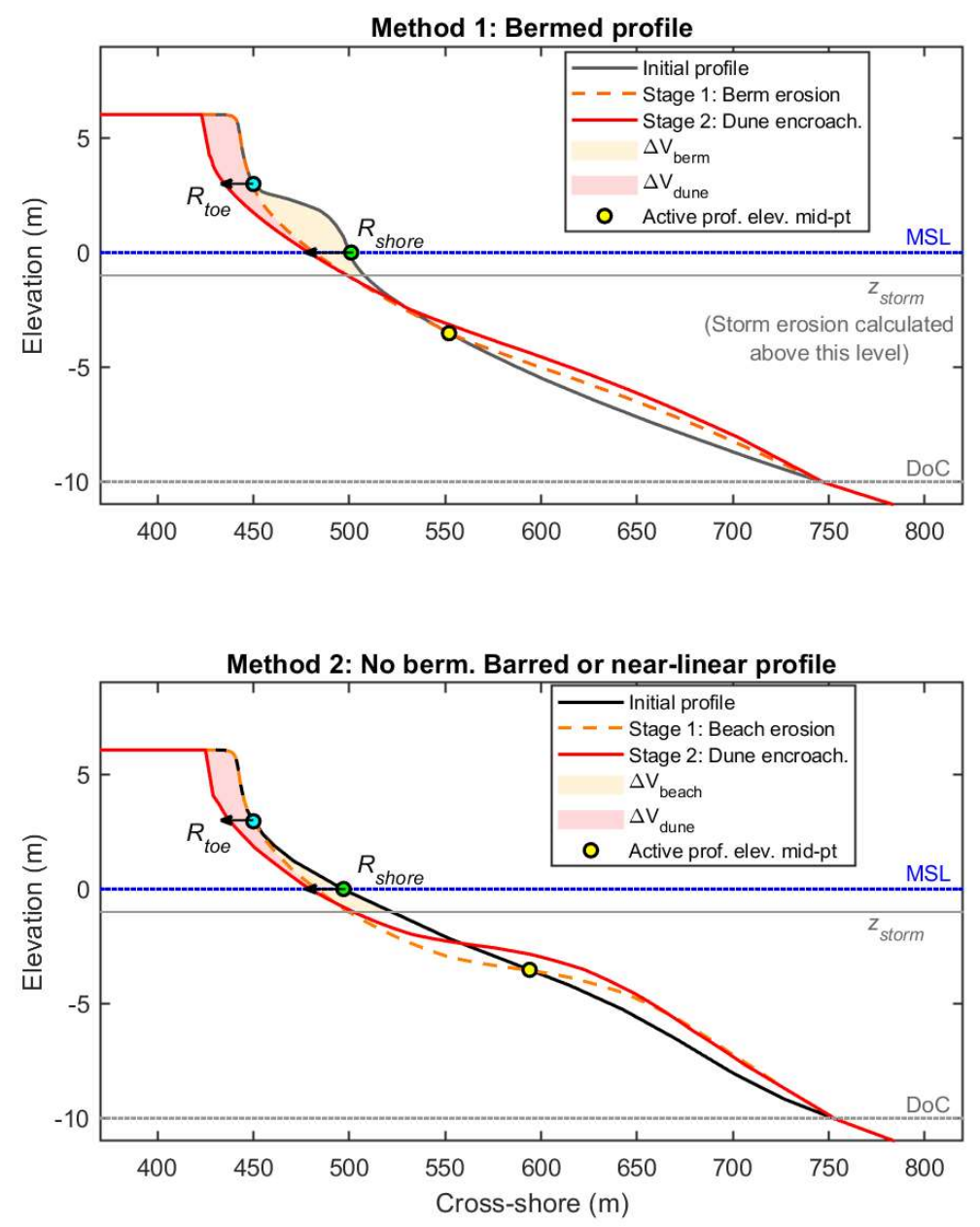

Figure 6. Short-term cross-shore variability (maximum storm demand), evaluated using two methods. Stage 1 is berm/beach erosion. Stage 2 is dune encroachment, found by applying the profile translation model (Fig. 2) iteratively through a range of SLR, until the target erosion volume $\left(\Delta V_{\text {storm }}\right)$ is reached. All profile changes conserve total volume. Variations between Method 1 and 2 are described in the text. 
A shoreface translation model for predicting future coastal change: ShoreTrans

Storm Demand Method 2: Linear to convex-up shorefaces, without berms

A second storm demand method is provided for beaches where no clear berm exists and Eq. 8 provides a poor fit (e.g., Perranporth, Section 3). This method requires an additional input, specifying the ratio of beach erosion to dune erosion $(\beta)$. This ratio can be determined through observation (used for Perranporth in Section 3); however, we know of no generalised method to estimate $\beta$.

1. For beach erosion, volume is subtracted from the top-half of the profile as a half-wavelength Sine-curve, with an equivalent volume added to the bottom half of the profile (Fig. 6b, Stage $1, \Delta V_{\text {beac }}=\beta \Delta V_{\text {storm }}$ ).

2. Dune erosion is applied as per Method 1, applying a SLR-type profile translation until the required volume is reached (Fig. $6 \mathrm{~b}$, Stage $2, \Delta V_{\text {dune }}=[\beta-1] \Delta V_{\text {storm }}$ ).

\section{Long-term trend onshore/offshore transport from the lower shoreface}

In addition to short-term variability in cross-shore transport (Fig. 6), we require a method to address gradual net onshore transport from the lower- to the upper shoreface (Dean and Houston, 2016), when a profile is out of equilibrium with forcing conditions. In this instance, sediment is brought onshore from the lower zone, which is inactive on short term scales, forced by wave asymmetry to the upper zone, where material is regularly re-worked through cross-shore processes. Conversely, diffusive and gravitional processes [25], as well as mega-rips [44,45] may move material downslope to the lower shoreface. In ShoreTrans, transport between the upper and lower shoreface is specified as a volume rate, with offshore as positive, with the lower profile lowered/raised between $Z_{D 1}$ and $Z_{D 2}$, shaped to a half-wavelength Sine-curve. The upper shoreface is raised/lowered uniformly until the gain/loss from the lower shoreface is balanced, applying smoothing at $Z_{D 1}$ to avoid a step.

\subsection{Trend change, rotation, sources/sinks and alongshore balancing within embayments Volume gains/losses, absent SLR}

Changes to total profile volume may occur due to a variety of processes, including: (i) longshore transport gradients; (ii) short-term beach rotation; (iii) headland bypassing; (iv) exchange between the shoreface and estuaries; and (v) dredging / nourishment activities. ShoreTrans simulates inputs and outputs to the profile budget, represented by non-zero values for $\Delta V$ in Eq. 4, by translating the profile on- or offshore, in the absence of SLR. This is the same method as applied in Fig. 2, with $\Delta S=0$, i.e., the profile is not raised (skip step Fig. $2 b$ ) prior to translation. 
The model can be run for a known rate of shoreline change (e.g., from surveying observations) or a known rate volume change (e.g., calculated from modelled longshore transport gradients). Examples of volume gain and loss are indicated (Fig. 7), which can be applied at the dune toe or at the berm crest (by specifying different values of $X_{C}, Z_{C}$ ). Applying volume change at the berm crest may be more suitable for modelling short-term rotation, where beach width can rapidly change, while the dune remains relatively stable (e.g., Narrabeen, Australia; [46]).
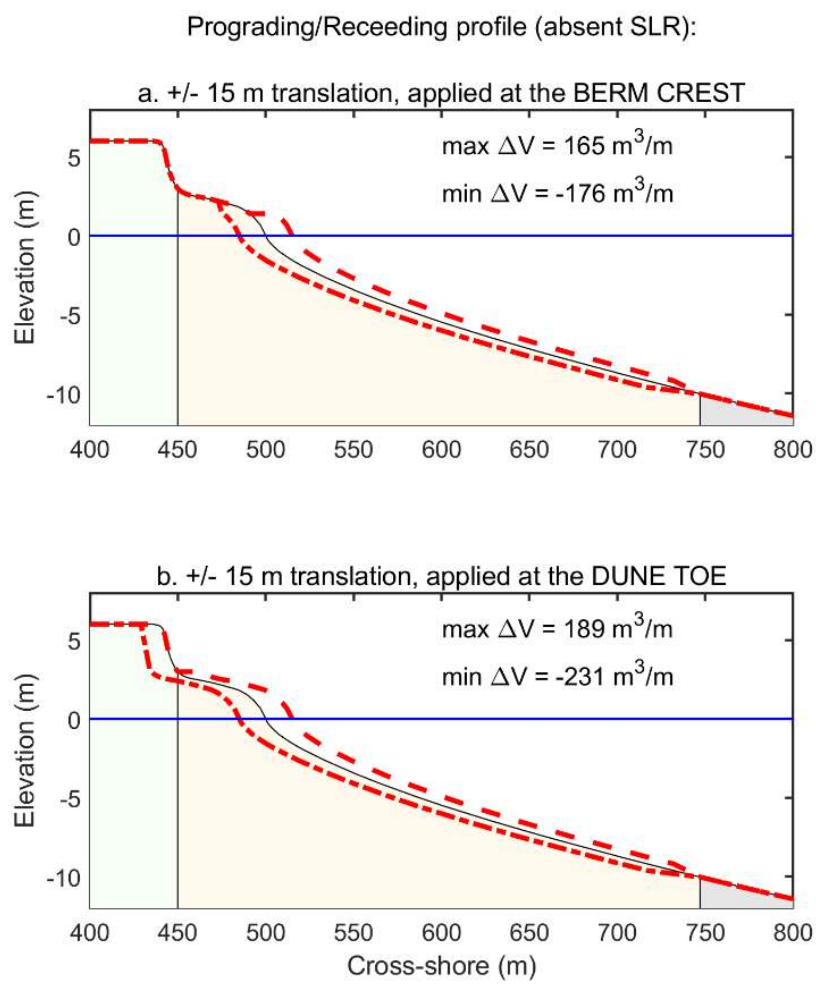

Figure 7. Methods for representing an accreting or eroding profile, with a net change to profile volume. This is the same method as Fig. 2, with $\Delta S=0$ (i.e., the profile is not raised prior to translation).

\section{Alongshore-balancing within embayments, extending from $2 D$ to $3 D$}

The method shown in Fig. 7 is suitable for estimating long-term trends and short-term variability in longshore transport within an embayment, e.g., at Start Bay in the UK, where multi-decadal unidirectional flux is overlain by short-term oscillations $[47,48]$. However, for cross-shore dominated embayments, where rotation is insignificant, such as Perranporth [49], a different approach is required to account for alongshore sediment redistribution.

Considering a closed embayment backed by cliffs in some sections and dunes in others, dune erosion will be distributed unevenly across the bay. Initially, the eroded dune sediment is likely to be deposited in front of the dunes. Over time, it can be expected that volume eroded from the dunes will become evenly distributed across the entire alongshore extent of the bay. ShoreTrans accounts for this effect 
in a two-step process by calculating dune erosion separately for each profile, then combining this into a shared pool of dune erosion. For each profile, the initial translation gives $\Delta V_{\text {shoreface, } 1}+$ $\Delta V_{\text {dunes }, 1}=0$ (volume is initially conserved within the profile), or alternatively $\Delta V_{\text {shoreface, } 1}=$ $-\Delta V_{\text {dunes, } 1}$. The dune pool ( $\left.\Delta V_{\text {DunePool }}\right)$ is divided out evenly along the beach, and as per Eq. 4 , the profile translation distance which balances the volume change is determined. Thus, for each profile, the longshore per unit $\left(\mathrm{m}^{3} / \mathrm{m}\right)$ balance is: $\Delta V_{\text {shoreface, } 2}=-\Delta V_{\text {DunePool }}$ (volume is now conserved within the embayment).

\subsection{Probabilistic uncertainty and choice of inputs to model applications}

Coastal management has seen an increasing move toward probabilistic, and away from deterministic, techniques to address uncertainty. We follow the approach of similar efforts $[10,29,30,50]$, using a probability density function (PDF) for key inputs to the model, e.g., depth of closure and sea-level rise (Fig. 8). A normal or triangular PDF (Fig. 8) can be selected. A selection of random cases are sampled from the PDF and a translated profile is generated for each case ( $n=1000$ in Fig. 8). The resulting envelope of profiles can be used to visualise the potential range of shoreface change (Fig. 8c) and shoreline recession can then be viewed as a probabilistic histogram, with percentile likelihoods (Fig. $8 d)$.
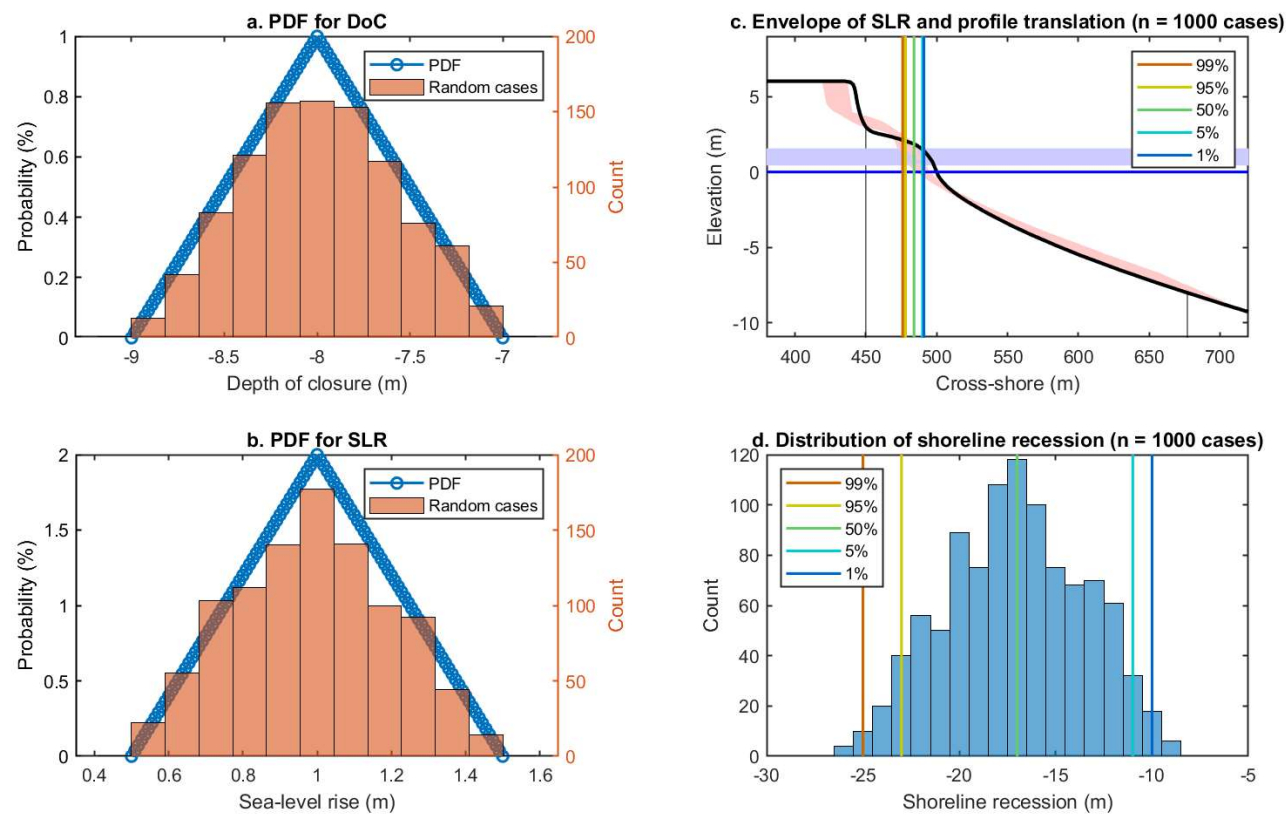

Figure 8. Probabilistic treatment of uncertainty within ShoreTrans. 
For the model applications in Section 3 (Perranporth) and Section 4 (Start Bay), we use a triangular distribution. This simple distribution is best used when there is some idea of a most likely value and the upper and lower bounds, but the exact shape of the distribution is poorly understood [10]. For the applications, we use observations to inform the inputs where data exist, then use best estimates from the literature where no field data are available. The following applications are intended to demonstrate the capabilities of the model, while also providing a first-pass (non-exhaustive) assessment of future shoreline change for these two sites. More comprehensive future studies are required to address the finer details at each site, which is necessary to refine uncertainty bounds on the various inputs.

Sea-level rise

We opt to use SLR of 1-m over 100 years (i.e., from 2020 to 2120) for all scenarios. This is approximately equivalent to extrapolating the IPCC high-emissions scenario RCP8.5 to 2120, which estimates $\sim 0.7 \mathrm{~m}$ by 2100 . This approach provides a convenient benchmark for conceptualising SLR impacts (Section 5), while still being within the bounds of real-world estimates. Other input variables are site-specific and are introduced within Section 3 and 4. 


\section{Results, Site 1: Perranporth}

Perranporth Beach, Cornwall, UK (Fig. 9a-d) is a 3.5-km long, sandy, high-energy beach (annual mean $H_{s}=1.6 \mathrm{~m}$ and $T_{p}=10 \mathrm{~s}$ ), with a wide dissipative shoreface and active double-bar morphology covering the low-tide region to the inner-subtidal. Tidal regime is macrotidal with mean spring tide range $>6$ m. A limited section at the south of the beach has been extensively studied since 2006 (e.g., $[51,52,53])$, showing a characteristic annual oscillation of $\sim 50 \mathrm{~m}^{3} / \mathrm{m}$ of the intertidal volume (Fig. 9, 'Intertidal'), with periodic extreme events of $100-200 \mathrm{~m}^{3} / \mathrm{m}$ erosion that take multiple years for recovery (5-7 years). Initially, the system was inferred to be near-closed, with cross-shore stormrecovery processes dominating the transport budget. Only since 2016 has the sediment budget of the entire embayment been thoroughly studied [34,49], determining, unexpectedly, that the subtidal budget is wide-open ( $400 \mathrm{~m}^{3} / \mathrm{m}$ fluctuation in Fig. 9), likely due to highly energetic longshore (e.g., headland bypassing) and cross-shore processes (e.g., mega-rips) operating at significant depth $[49,54,55]$. The open nature of the system precludes an easy estimate of long-term (multi-decadal) trend rates, i.e., the noise due to natural short-term variability is much larger than the residual trend (Fig. 9 'Total'). As an alternative, the dune vegetation-line from satellite images has been examined, using the CoastSat software package [56], determining that the vegetation-line for the northern dunes has been relatively stable for the past 35 years (Fig. 9 'Dunes', black line), with $12 \pm 6 \mathrm{~m}$ of progradation over this period, determined by fitting a linear trend to the unsmoothed average vegetation line (Fig. 9 'Dunes', grey dots), with 95\% confidence intervals. This is an indicator the system is open, but dynamically stable, or has a marginally positive sediment budget, i.e., that gains through onshore transport (from below $Z_{D 1}$ ) and bypassing influx, likely outweigh mega-rip losses and bypassing loss over time $[49,55]$. A dynamically stable to gradually prograding system is also consistent with the conventional understanding of how similar systems work (e.g., $[17,40])$, and we will therefore use this as a guide to inputs. However, a future more exhaustive effort will be required to test the sediment budget assumptions of this first-pass investigation.

\subsection{Perranporth: Inputs to translation model}

Morphological data were obtained using a multi-method approach, with extensive details given in [49]. Profiles were extracted from a 2017 merged topo-bathymetry. A summary of model input parameters for Perranporth are given in Table 1. For depth of closure, the observed depth of morphological change is $D o C_{1}=15 \mathrm{~m}$ relative to datum, and the depth of no motion is $D o C_{2}=28 \mathrm{~m}$ (both values from [34]). Model input for upper depth of closure $\left(Z_{D 1}\right)$ uses a triangular distribution with [lower; upper] bounds of $\left[D o C_{1} ;\left(D o C_{1}+D o C_{2}\right) / 2\right]$, and a modal value as the midpoint between 
A shoreface translation model for predicting future coastal change: ShoreTrans

these, which equates to [ $15 \mathrm{~m}, 18.25 \mathrm{~m}, 21.5 \mathrm{~m}$ ]. This is similar to the approach of [10], though with a shallower maximum value. There is no consensus on how depth of closure should be addressed, and we will address uncertainty related to depth of closure selection in Section 5.

Inputs and outputs to the multi-decadal Perranporth sediment budget (Table 1, bottom half) are inferred from the stable to slowly prograding dune vegetation-line (Fig. 9, 'Dune') combined with the widely fluctuating multi-annual sediment budget [34,49]. Given an average height of $\sim 8 \mathrm{~m}$ of the foredune, dune coverage across $2 / 3$ of the beach length, and $12 \mathrm{~m}$ of dune-line progradation over 35 years, this gives a crude estimated annual input of $\sim 1.8 \mathrm{~m}^{3} / \mathrm{m} / \mathrm{yr}$. The input is inferred to be distributed between headland bypassing and cross-shore transport, and given the simplistic nature of the estimate, we apply wide uncertainty bands of $\pm 200 \%$, giving a range of -1.8 to $+5.4 \mathrm{~m}^{3} / \mathrm{m} / \mathrm{yr}$ across these two mechanisms (summing bypass and shoreface transport in Table 1). Absent field data, but consistent with [40], a dune accretion range of -0.25 to $0.75 \mathrm{~m}^{3} / \mathrm{m} / \mathrm{yr}$ is applied, with the central point in this range $\left(0.25 \mathrm{~m}^{3} / \mathrm{m} / \mathrm{yr}\right)$ equivalent to $5 \mathrm{~mm}$ annual vertical growth distributed over $50 \mathrm{~m}$ behind the foredune crest. These values are consistent with present understanding $([17,40])$ and are suitable for a first-pass assessment and for demonstration of the model, but a more detailed future effort will be required to better resolve these uncertainties.

A maximum storm demand of $200 \mathrm{~m}^{3} / \mathrm{m}$, used for estimating short-term cross-shore variability, was determined by taking the volume difference from the most eroded period on record (post the 201314 winter $[8,49])$, relative to the beach state at the time used for model inputs (2017). Due to the linear to convex-up shape of the Perranporth profile, Storm Demand Method 2 was applied (Section 2.4). An erosion distribution of $80 \%$ beach / $20 \%$ dunes was employed, based on observations [49].

Profile selection is simplified by taking only three profiles along the extent of Perranporth (Fig. 9a-d). Each of the profiles represents a different backshore morphology type, including: (P1) Northern 'perched' dunes, overlying a shallow bedrock substrate, representing $50 \%$ of the total shoreline length; (P2) Mid-beach cliffs, 33\% total length; and (P3) Southern dunes, with greater depth to bedrock and a shallower shoreface gradient, $17 \%$ total length. For P1, depth to bedrock is estimated at $7 \mathrm{~m}$ based on seismic surveys (work in preparation), with a horizontal depth from the foredune to the cliff face estimated as a minimum of $15 \mathrm{~m}$, based on observations that $>10 \mathrm{~m}$ of horizontal erosion [49] failed to expose the cliff face for sections of the northern dunes. The buried cliff is set to behave as a wall once exposed (as per Section 2.2 and Fig. 3). The exposed cliff at P2 is set to act as a wall. Choosing fewer profiles is done for clarity in this brief example application; however, a detailed application could take many profiles at fixed intervals along the bay or even a full 3D approach. 

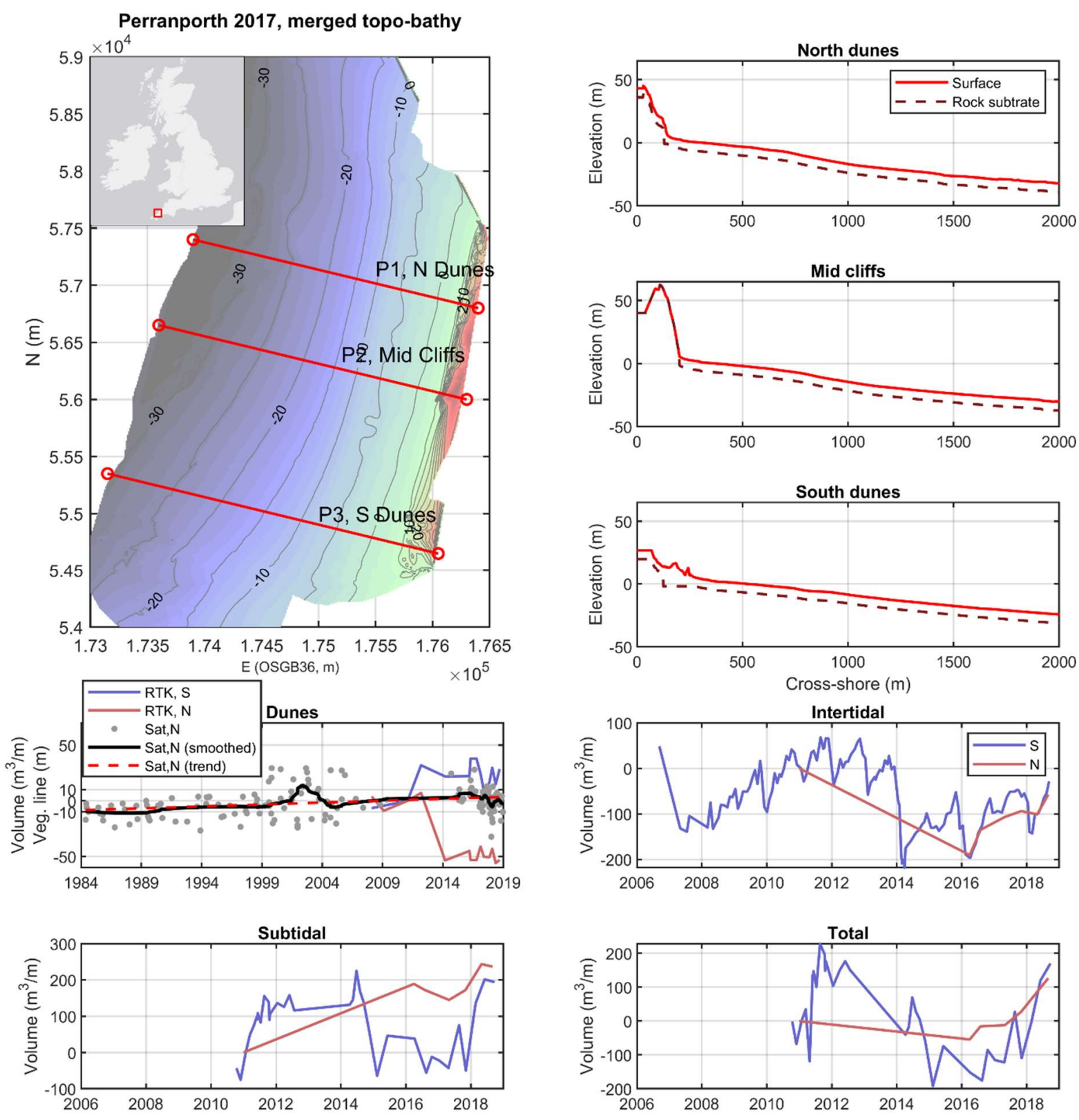

Figure 9. Perranporth Beach with morphological change time series. (Top left) plan view of beach morphology, (top right) three selected profiles; (bottom half) volume time series for each component of the system (Dunes, Intertidal, Subtidal) and the Total cross-shore system, for the southern and northern sectors. For 'Dunes' panel, 'RTK' is in units of volume alongshore, 'Sat' indicates the dune vegetation-line obtained from satellite imagery, with units of metres, the thick black line is a Robust Loess smoothing over $30 \%$ of the dataset, the dashed-red line is a linear trend. 
Table 1: Perranporth model parameters

\begin{tabular}{|c|c|c|c|c|}
\hline Input parameter & Low bound & Mean estimate & High & Comment \\
\hline \multicolumn{5}{|l|}{ Elevations (m) } \\
\hline $\operatorname{SLR}(\mathrm{m})$ & 0.5 & 1.0 & 1.5 & $\begin{array}{l}1 \mathrm{~m} \text { over } 100 \text { years. Equivalent } \\
\text { to extrapolating RCP8.5 to } \\
2120 .\end{array}$ \\
\hline $\begin{array}{r}-Z_{D 1}, \text { upper closure } \\
(\mathrm{m})\end{array}$ & 15 & 18.25 & 21.5 & $\begin{array}{l}\text { Low bound is observed } \mathrm{DoC}_{1} \text {, } \\
\text { high bound is }\left(\mathrm{DoC}_{1}+\mathrm{DoC}_{2}\right) / 2 \text {, }\end{array}$ \\
\hline & & & & {$[34]$} \\
\hline$-Z_{D 2}$, lower closure & - & 28 & - & From [34]. \\
\hline$(\mathrm{m})$ & & & & \\
\hline \multicolumn{5}{|l|}{ Inputs / Outputs } \\
\hline $\begin{array}{r}\text { Dune vertical } \\
\text { accretion }\left(\mathrm{m}^{3} / \mathrm{m} / \mathrm{yr}\right)\end{array}$ & -0.25 & 0.25 & 0.75 & $\begin{array}{l}\text { Inputs / outputs represent } \\
\text { first-pass estimates, guided by }\end{array}$ \\
\hline Headland bypass & -0.9 & 0.9 & 2.7 & an understanding of typical \\
\hline$\left(\mathrm{m}^{3} / \mathrm{m} / \mathrm{yr}\right)$ & & & & values $[17,40]$ \\
\hline Lower shoreface & -0.9 & 0.9 & 2.7 & \\
\hline \multicolumn{5}{|l|}{ transport $\left(\mathrm{m}^{3} / \mathrm{m} / \mathrm{yr}\right)$} \\
\hline \multicolumn{5}{|l|}{ Cross-shore variability } \\
\hline $\begin{array}{l}\text { Volume change } \\
\qquad\left(\mathrm{m}^{3} / \mathrm{m}\right)\end{array}$ & - & -200 & - & $\begin{array}{l}\text { Observed range (Feb } 2014 \text { to } \\
\text { Aug 2017). }\end{array}$ \\
\hline
\end{tabular}

A triangular distribution (Section 2.7) was used to randomly select $n=1000$ scenarios using the above parameter ranges for use in Section 3.2.

\subsection{Perranporth: 100-year profile translation, with probabilistic uncertainty}

The translation model was applied to Perranporth using encroachment mode (Section 2.3), given that the large dunes and steep substrate gradient will act to prevent rollover from occurring. The results are given in Figure 10. This application of the model involves 1 time-step (2020 to 2120) with multiple samples for each profile, randomly selected across the input ranges in Table 1, using a triangular PDF. For P1, with 1-m SLR, the profile is predicted to recede to the buried cliff face (Fig. 10, top-left), where a maximum recession limit for the dune toe is reached. For higher rates of translation, the 'wall demand' increases ( $\Delta V_{\text {wall demand }} ;$ Fig. 3 ) and the back of the profile flattens (spread of grey envelope in Fig. 10, top-left). For the exposed cliff face in P2 (Fig. 2, mid-left), $\Delta V_{\text {wall demand }}$ is also a factor and 
produces flattening of profile at the cliff base. For P1 and P2, the range of cross-shore variability (pink dashed line) is greater than the envelope of trend change. For P3 (Fig. 10, bottom-left), an isolated foredune is present, which is eroded in some scenarios and preserved in others (grey envelope). Crossshore variability is less for $\mathrm{P} 3$ as dunes are available (post-SLR) to satisfy storm demand, whereas for the cliff-backed profiles (P1, P2), only beach volume is available.
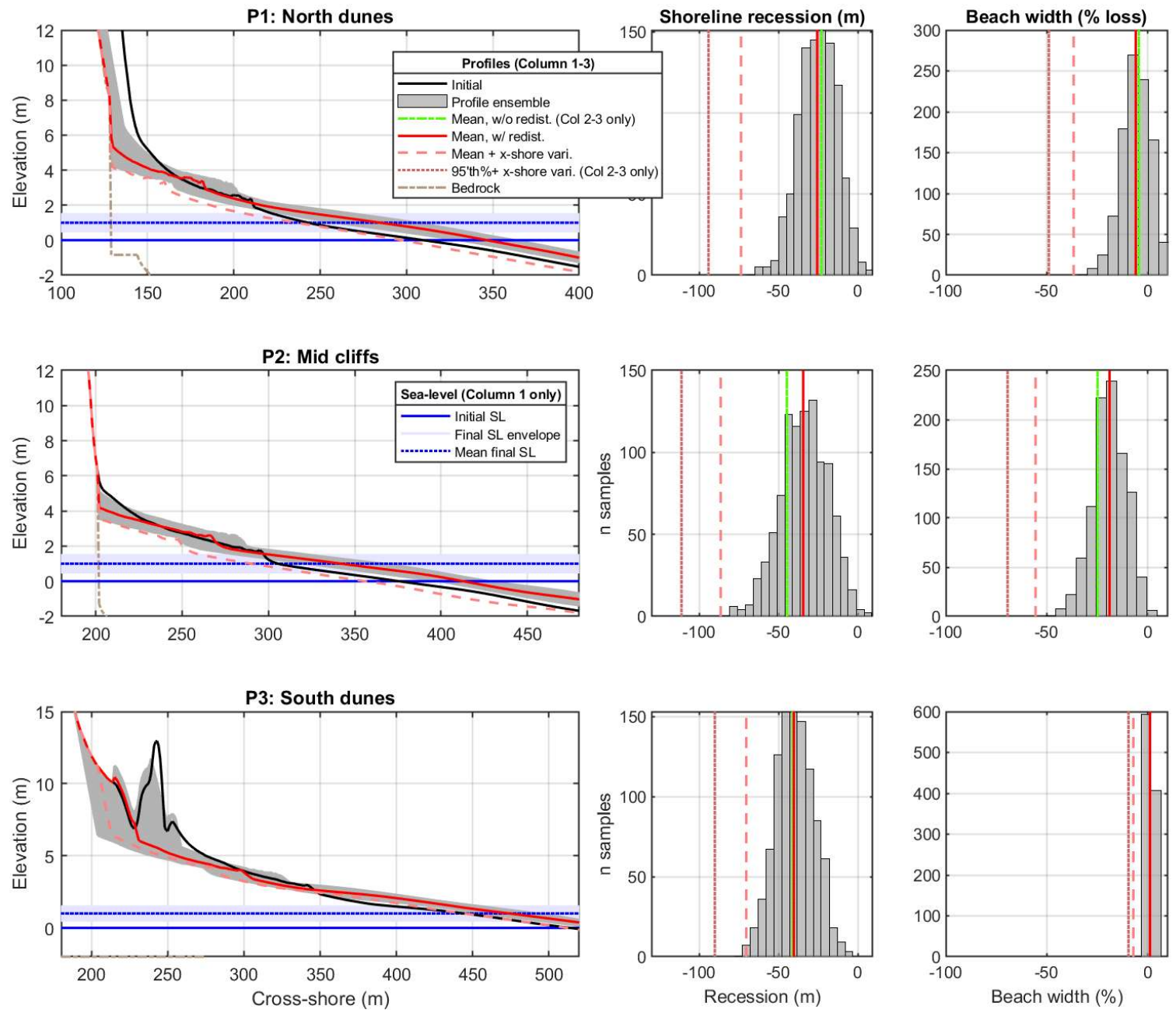

Figure 10. PPT profile translation with projected shoreline recession and beach width reduction, for $1-\mathrm{m}( \pm 0.5$ m) sea-level rise over 100-years. (First column) Cross-sectional view of initial (black) and final (red) profiles, with profile ensemble envelope (grey), short-term cross-shore variability (pink dashed) and rock layer (brown dash-dot). (Middle column) Shoreline recession histogram, with lines as per Col. 1, adding mean recession ignoring alongshore redistribution (green) and 95'th percentile trend recession plus short-term variability (pink dotted). (Third column) histogram of beach width percentage loss, with colour coding as per Col. 2.

The shoreline recession histograms (Fig. 10, $2^{\text {nd }}$ Col.) indicate significant variability alongshore. P1 shows the lowest median recession ( $35 \mathrm{~m}$ ) as the dune initially acts as a buffer, providing sediment to 
the shoreface as it is eroded. P2 shows greater mean recession due to the absence of dunes. However, the middle profile also benefits the most once the eroded dune volume is redistributed evenly alongshore (Fig. 10 middle, green line; method described Section 2.5), with a reduction in predicted recession of $10 \mathrm{~m}$ (Fig. 10, middle; distance from green line to red line). The southern profile (P3) is predicted to have the highest mean recession rate, primarily due to the lower gradient of the shoreface. Change in predicted beach width also varies dramatically alongshore (Fig. 10, Col. 3) and is unrelated to shoreline recession. The perched-dune (P1) and cliff-backed (P2) profiles begin to lose beach width as the shoreline recedes while the dune-toe cannot translate onshore due to the hardrock boundary. This results in moderate loss of beach width for mean trend rates (10\% to $30 \%$ ) with $>60 \%$ reduction in beach width (Fig. 10, mid-right) at the extremes of cross-shore variability, i.e., after extreme storms.

\subsection{Perranporth: Time series for 2 -m of SLR over 150 -years}

We now apply the model to the northern Perranporth dunes (P1, Fig. 10) in an iterative time-series with 10-year increments (Fig. 11). For brevity and clarity, this application uses only the mean (peak probability) parameter values from Table 1, i.e., uncertainty ranges and cross-shore variability are not calculated. A hypothetical exponentially increasing sea-level time series was calculated with length 150-years (Fig. 11a) to illustrate the time-dependent beach response. In this instance, 1-m of SLR occurs over the first 100-years (as per Section 3.1), while an additional 1-m rise is set to occur over the subsequent 50 years. The extended timeframe is required to illustrate the impact on beach width beyond 2120 .

In this scenario, it takes approximately $70-80$ years for the dune-toe to encroach back to the buried cliff face (Fig. 11b). During this time, there is a low rate of recession ( $10 \mathrm{~m}$ by 2100 ; Fig. 11c), while the beach width marginally increases, due to the assumption of marginally positive sediment budget (bypassing and onshore transport, Table 1). A rapid change occurs after 2100 , once the cliff is exposed and sea-level rise accelerates. Now, the beach width declines at the same rate as the shoreline position, with an estimated $\sim 50 \mathrm{~m}$ loss of beach width by 2170 , after 2-m of SLR. This highlights the importance of including the non-erodible substrate, combined with the analysis of beach width in addition to shoreline recession. 

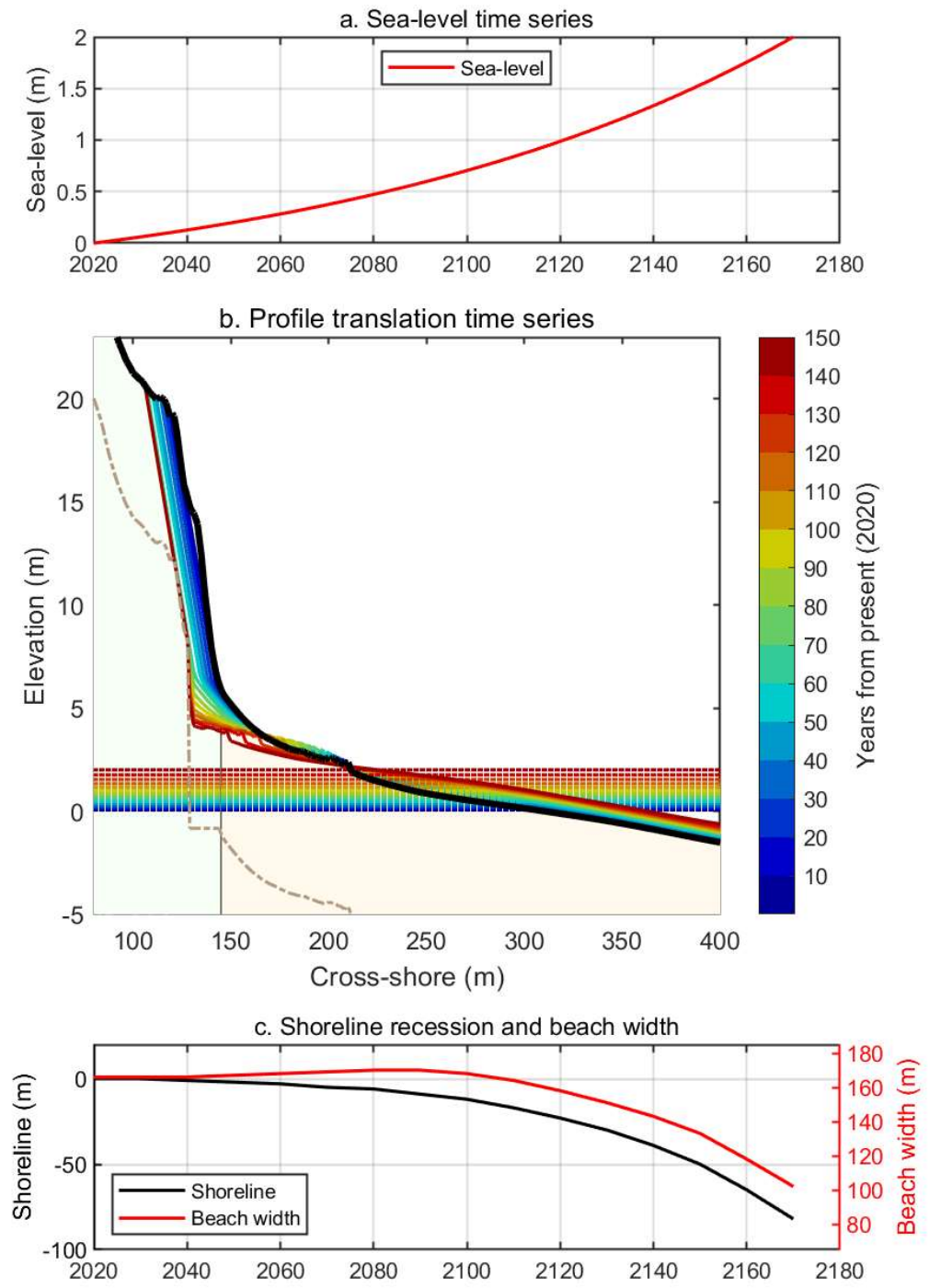

Figure 11. Example profile translation time series for SLR of 2-m over 150-years, for profile P1 (North Dunes, Fig 1), showing shoreline recession and beach width reduction. The first 100-years of the sea-level curve (1-m SLR) is equivalent to the scenarios shown in Fig. 10 and Fig. 12. 


\subsection{Perranporth: Recession and beach width summary}

A summary of predicted coastal change at Perranporth to 2120 is summarised in Figure 12, comparing ShoreTrans against estimates using the standard Bruun-rule (Eq. 2). Uncertainty is represented with error bars of \pm 1.96 standard deviations of the ensemble sample ( $n=1000$; histograms in Fig. 10$)$. Relative to the new model, the Bruun-rule underpredicts shoreline recession (Fig. 12, top) in front of the exposed cliff (P2), and overpredicts where large erodible dunes are present (P1, P3). These variations are substantial (up to $15 \mathrm{~m}$, or 33\%, for P1 'Bruun' vs 'No redist.'). However, in all instances, the error bars are overlapping, suggesting Bruun is still an acceptable first-pass estimate for recession on this beach type. When cross-shore variability is added to the mean recession values (i.e., adding the maximum potential short-term storm erosion to the trend rate after 100-years), maximum recession rates are 1.5 to 3 times the base recession rate. Alongshore redistribution of dune erosion volume, where the sediment erosion from dunes is evenly distributed alongshore, is shown to be most critical for the cliff-backed profile (P2), with recession dropping from $50 \mathrm{~m}$ to $<40 \mathrm{~m}$ once redistribution is included.

The Bruun approach, and many recent efforts to predict future coastal change, focus on shoreline recession while neglecting beach width (Fig. 12, bottom). ShoreTrans predicts the greatest beach loss for the cliff-backed profile (P2, >20\%), followed by the 'perched dunes and buried cliff' profile (P1), which lags due to buffering initially provided by the dunes (Fig. 12). The cliff-backed profiles show an even greater beach width loss for extreme conditions, when cross-shore storm demand is added (>60\% for P2), as the 'wall-demand' effect ([28]; Fig. 3) exacerbates storm impacts. By comparison, the southern dune profile (P3), which has no substrate exposure, shows marginal beach width growth (due to the assumed positive sediment budget, Table 1), with minor width reduction during extreme conditions. 
A shoreface translation model for predicting future coastal change: ShoreTrans
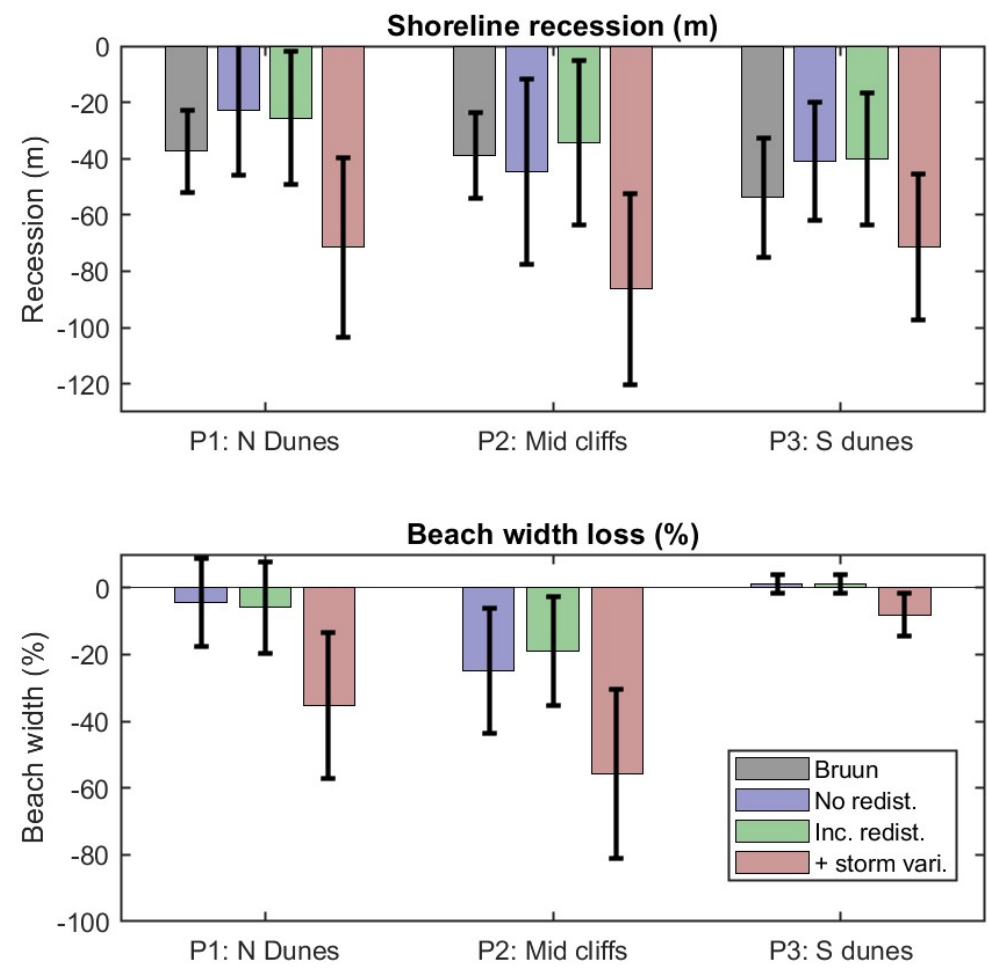

Figure 12. Summary of shoreline recession and beach width prediction for Perranporth beach, assuming $1+/$ $0.5 \mathrm{~m}$ of SLR by 2120 . The Bruun-rule is used for comparison of shoreline recession rates. Error bars indicate 1.96 standard deviations across the profile ensembles (as indicated in Fig. 11). 


\section{Results, Site 2: Start Bay}

Start Bay, Devon, UK (Fig. 13), is a 12-km long embayment, with multiple fine-gravel beaches divided by small rocky headlands [47]. From south to north, the beaches include: Hallsands, Beesands, Slapton Sands and Blackpool Sands. Slapton Sands is the longest beach, at >4 km length, with a narrow (100$200 \mathrm{~m}$ wide) and low ( $\sim-7 \mathrm{~m}$ above mean sea-level) barrier that is backed by a lagoon and has a road constructed along the crest. Across other sections of the bay, the barrier backs onto wetlands or cliffs. Built-up areas, including the villages of Torcross and Beesands, are heavily defended, with rockarmour and seawalls protecting buildings that would otherwise fall within the active shoreface. All barriers are comprised of fine gravel, with a transition to sand at $10 \mathrm{~m}$ water depth [57]. Given that the barrier is pure gravel and the lower shoreface is shelly sand, it is a reasonable assumption that there is no exchange between the upper and lower shoreface. Wave heights are generally low $(<1 \mathrm{~m})$, apart from during storm events ( $H_{s}$ up to $5 \mathrm{~m}$ ). The wave climate is bi-directional, with dominant swell waves from the SW refracted over Skerries Bank [58] into the bay, driving northward transport, and less frequent short-period easterly events, driving southward flux. Tidal regime is meso-macro tidal, with a $4.3 \mathrm{~m}$ mean spring range.

Rates of longshore transport have been extensively studied at Start Bay, and the system has been found to be closed to the south of Hallsands and north of Blackpool Sands [47]. A long-term (>100 years) south to north longshore transport trend (Fig. 13c) may have contributed to the destruction of an old fishing village $[58,59]$, in addition to aggregate dredging of the shoreface. Short-term changes in longshore flux, forced by variations in the bi-directional wave climate, result in rapid changes in beach width due to rotation $[47,48]$, particularly near headlands (Fig. 13b, d). Beach profile surveys conducted regularly since 2007 (Fig. 13e) indicate that shorelines along the southern two-thirds of the bay are receding at up to $1 \mathrm{~m} / \mathrm{yr}$, while the far-northern profiles are rapidly accreting at 2-5 m/yr, much of which is due to northward headland bypassing and 'full embayment rotation' during the exceptional 2013/14 winter [47]. A longer record of shoreline change was obtained from satellite data [56], which is generally consistent with the trends observed in the survey data (Fig. 13e).

\subsection{Start Bay: Inputs to translation model}

As for Perranporth, the inputs for Start Bay are considered suitable for a first-pass coastal change assessment and demonstration of the model; however, a future more detailed investigation will be required to robustly address uncertainties in the inputs and morphological complexity within the system. Morphological data were obtained using a multi-method approach, as described in [47]. The profiles used herein were extracted from a 2018 merged topo-bathymetry [47]. A summary of input 
parameters is provided in Table 2. SLR was projected at $1 \pm 0.5 \mathrm{~m}$ by 2120 , as for the Perranporth application (Section 3.2). Upper depth of closure was obtained from observations around an extreme event [48], taking the observed depth of morphological change as the shallow bound, with a range of $2 \mathrm{~m}$, increasing from south ( $<10 \mathrm{~m}$ depth) to north (up to $12 \mathrm{~m}$ depth). As stated above, an assumption of zero-transport is applied between the upper- and lower shoreface, due to the presence of the gravel-sand transition. Therefore, no lower depth of closure is specified, as no change to the lower shoreface will be applied within the model.
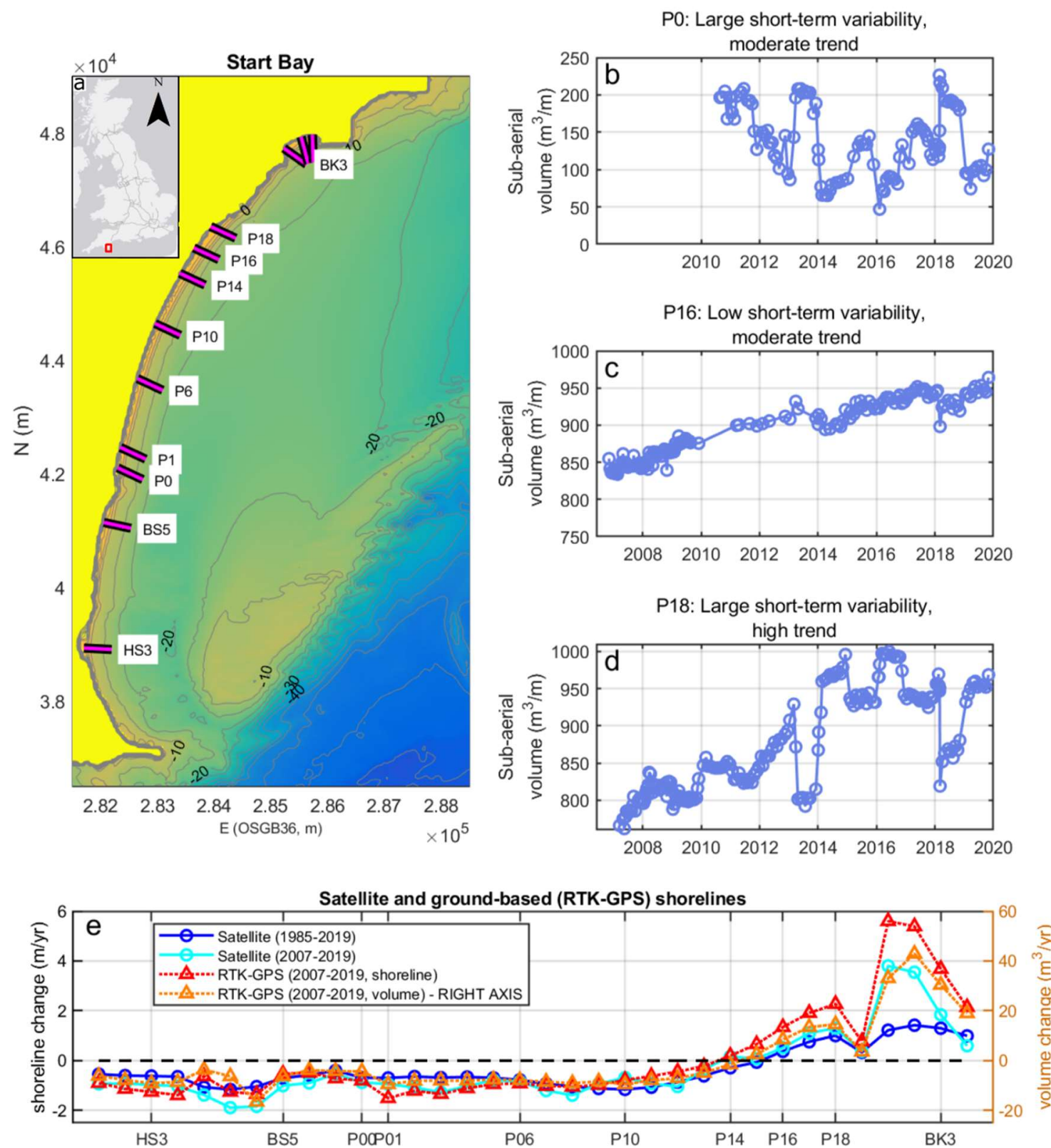

Figure 13. Start Bay morphology and morphologic change. (a) Plan view with profiles indicated; (b-d) Selected profile volume time series', illustrating differing behaviours in trend and variability; and (e) alongshore profile position against rates of shoreline change, comparing rates derived from satellite imagery and ground-based surveys. 
Inputs and outputs to the Start Bay application are applied as a gross rate based on the observed rates of shoreline change, with an assumption that $100 \%$ of volume change is attributable to longshore flux gradients. The process is as follows: (i) trend changes to shoreline position were determined as a rate ( $\mathrm{m} / \mathrm{yr}$ ) based on the long-term (1985-2020) satellite derived rate; (ii) uncertainty bounds of $\pm 0.3 \mathrm{~m} / \mathrm{yr}$ were applied, rounding up the $95 \%$ confidence interval on the annual shoreline trend, using unsmoothed satellite based shoreline positions [max. uncertainty is $0.24 \mathrm{~m} / \mathrm{yr}$, rounding to $0.3 \mathrm{~m} / \mathrm{yr}$ ]; (iii) the translation model was initially run with zero SLR to determine the rate of volume change that equates to a given rate of shoreline change for each profile, thereby accounting for volume change across the entire active shoreface; (iv) the SLR projection was then conducted, iterating the profile through a range of translation distances (Fig. 2), and using the profile-specific rates of volume change to balance Eq. 4. Trend rates, with upper and lower uncertainty bounds, are listed in Table 2. Shortterm variability due to longshore transport (i.e., rotation), was estimated as a bulk volume based on observations (Fig. 13 b-d; $[47,48]$ ), with higher values generally adjacent to headlands and toward the north of the embayment. Short-term cross-shore variability was omitted from the assessment as Start Bay is dominated by alongshore transport and also because the storm-erosion methods (Section 2.4) are designed for sandy beaches, which are likely ill-suited to application to gravel barriers.

This approach assumes: (i) present trend rates of volume change are likely to continue until 2120; (ii) sufficient sediment volumes are present at the southern end of the bay for the trend to be maintained; and (iii) the barrier will be stationary in the absence of SLR or longshore flux gradients. The validity of these assumption will be discussed in Section 5. The 'wall demand' method (Section 2.2) is applied to the sheet piling wall for the profile at Torcross (PO, Fig. 14a). For all other sections of the barrier, both the 'rollover and keep-up' and the 'encroach' methods were tested (Section 2.3, Fig. 5). Implicit in this approach is an assumption that the section of barrier that is currently crested by an asphalt road (P1 to P14, Fig. 13) will be permitted to naturally roll back. 
Table 2: Start Bay model parameters

\begin{tabular}{|c|c|c|c|c|}
\hline Input parameter & Low & Mean estimate & High bound & Comment \\
\hline \multicolumn{5}{|l|}{ Elevations (m) } \\
\hline $\operatorname{SLR}(m)$ & 0.5 & 1.0 & 1.5 & \\
\hline $\begin{array}{l}Z_{D 1} \text {, upper closure, } \\
\text { at south end of bay }(\mathrm{m})\end{array}$ & 8 & 9 & 10 & $\begin{array}{c}\text { Low bound from } \\
\text { observation [48], high }\end{array}$ \\
\hline $\begin{array}{l}Z_{D 1} \text {, upper closure, } \\
\text { at north end of bay }(\mathrm{m})\end{array}$ & 10 & 11 & 12 & $\begin{array}{c}\text { bound inferred from } \\
\text { depth of gravel barrier). }\end{array}$ \\
\hline \multirow[t]{2}{*}{ Profile trend rates of change $(\mathrm{m} / \mathrm{yr})$} & & Mean estimate & & Short term variability \\
\hline & & $( \pm 0.3 \mathrm{~m} / \mathrm{yr})$ & & (rotation) $\left( \pm m^{3}\right)$ \\
\hline HS3 (Hallsands) & & -0.6 & & 50 \\
\hline BS5 (Beesands) & & -0.7 & & 50 \\
\hline P0 (Torcross, South Slapton Sands) & & -0.7 & & 200 \\
\hline $\mathrm{P} 1$ & & -0.7 & & 50 \\
\hline P6 & & -0.8 & & 50 \\
\hline P10 & & -1.2 & & 75 \\
\hline P14 & & -0.3 & & 50 \\
\hline P16 & & 0.4 & & 50 \\
\hline P18 (North Slapton Sands) & & 1.0 & & 200 \\
\hline BK1 (West Blackpool Sands) & & 1.2 & & 400 \\
\hline BK3 & & 1.3 & & 150 \\
\hline BK4(East Blackpool Sands) & & 1.0 & & 300 \\
\hline
\end{tabular}

*A triangular distribution (Section 2.7) was used to randomly select $n=1000$ scenarios using the above parameter ranges for use in Section 3.2.

\subsection{Start Bay: 100-year profile translation, with probabilistic uncertainty}

A wide range of profile translation responses are predicted across Start Bay. Three examples are selected: (i) a wall-backed profile, exposed to high rates of short-term variability and likely long-term extinction [Fig. 14, top]; (ii) a narrow receding section of the lagoon-backed barrier [Fig. 14, middle]; and (iii) a wide section of the barrier that is predicted to prograde in the future.

The first profile (P0, Fig. 14, top) is protected by cemented rip-rap on the upper profile, bounded below by sheet-piling (solid vertical black line). The initial PO profile has a large range of natural variability (Fig. 14, top, grey dashed bars), due to alongshore rotation processes, and the location of the profile adjacent to a headland. Under all scenarios, this profile is predicted to erode to below the raised sea- 
level. The toe of the beach is submerged by $\sim 1 \mathrm{~m}$ when trend rates of shoreline change are ignored (green line). When the trend rate of $0.7 \mathrm{~m} / \mathrm{yr}$ is included, PO erodes severely such that the profile immediately offshore the wall erodes below mean low water springs (MLWS $=-2 \mathrm{~m}$ ). We have imposed MLWS as a maximum erosion limit for the top of the profile and therefore the profile can be considered fully depleted. If this limit is not imposed, the entire profile would erode down to the upper depth of closure. As the profile is fully depleted back to the wall for all scenarios, both short-term variability and shoreline recession converge on a single value (Fig. 14, top-right). The progressive erosion of this profile is explored further in Section 4.3.

The second profile (Fig. 14, middle-row) includes various scenarios for a low-barrier, backed by a lagoon. Here, SLR translation is secondary to the trend rate of change (compare the green and red lines), and natural variability is low as it is situated towards the centre of the embayment where rotation effects are reduced. Comparing the 'encroachment' and 'rollover and keep-up' scenarios (yellow and red lines respectively), encroachment results in $10 \mathrm{~m}$ less shoreline recession. However, this effect is dwarfed by the total amount of recession $(\sim 110 \mathrm{~m})$ and also by the range of uncertainty in the ensemble ( $\pm 40 \mathrm{~m}$ ). The third profile (Fig. 14, bottom) is predicted to have a SLR recession impact of $-20 \mathrm{~m}$, which is overwhelmed by the long-term positive longshore budget and progradation trend. Despite the large range of natural variability ( $\pm 200 \mathrm{~m}^{3}$ for $\mathrm{P} 18$ ), the range of uncertainty due to the trend change is larger still (pink dashed and dotted lines fall well within the grey shaded envelope / histogram). Beach width gain/loss for these cases are: $-100 \%$ for P0 (in all cases), $0 \%$ change for P1 where the barrier is assumed to translate onshore and maintain width, and approximately $+50 \%$ for $\mathrm{P} 18$ which is prograding and is backed by a cliff. 

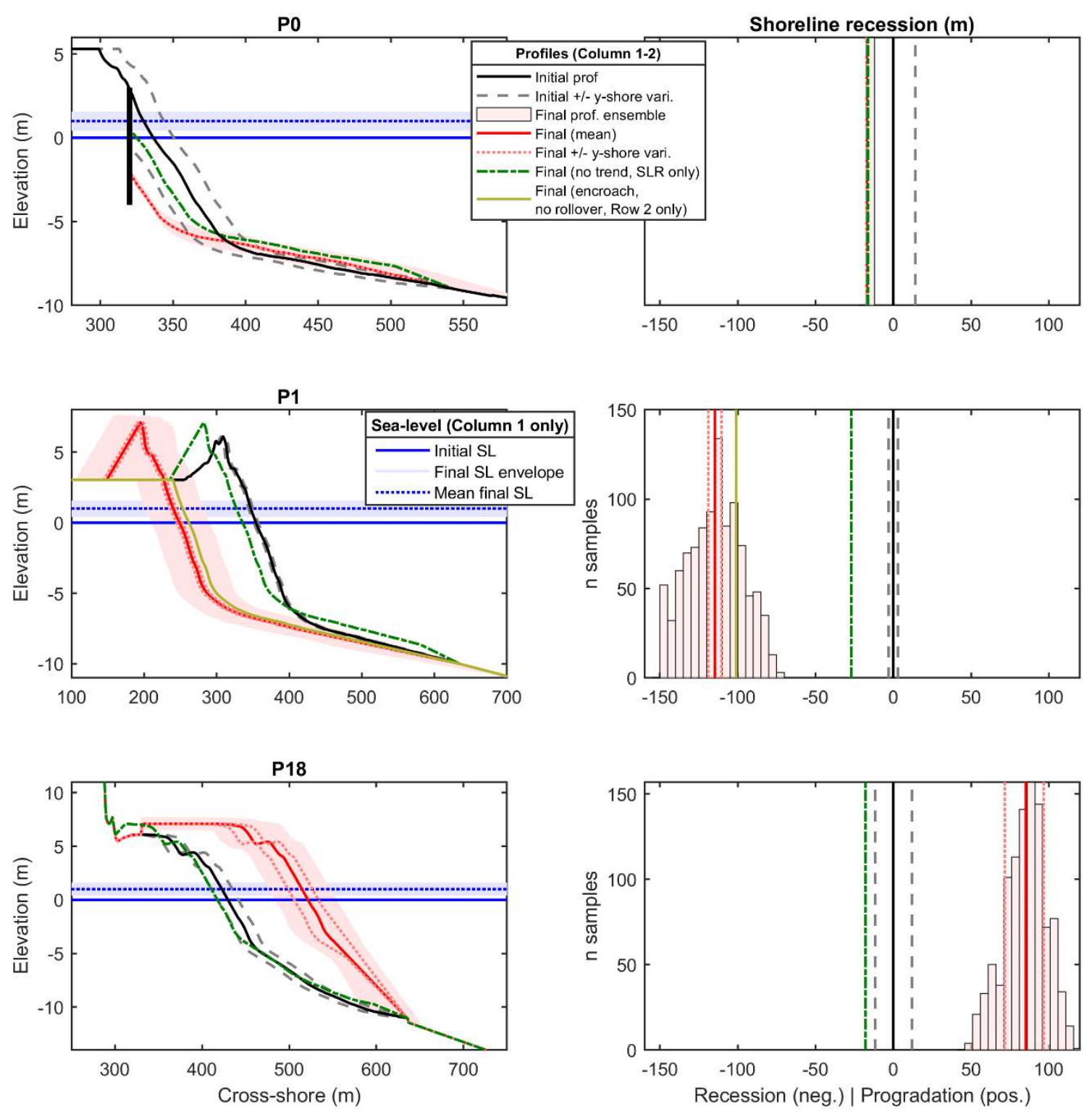

Figure 14. Start Bay profile translation for three selected profiles with projected shoreline recession and beach width reduction, for 1-m $( \pm 0.5 \mathrm{~m})$ SLR over 100-years. (First column) Cross-sectional view of initial (black) and final (red) profiles, pre-SLR alongshore variability (grey dashed), with post-SLR profile ensemble envelope (pale pink), post-SLR short-term alongshore variability (pink dotted) and post-SLR profile, ignoring trend (green). (Right column) Shoreline recession histogram, with line colour and style as per Col. 1. 


\subsection{Start Bay: 100-yr time series}

ShoreTrans is now applied in time-series mode to the heavily defended profile P0, with 1-m SLR (Fig. 15) for the satellite-derived trend shoreline rate of $-0.7 \mathrm{~m} / \mathrm{yr}$ (Fig. 15, left column) and for zero trend, conserving volume (Fig. 15, right column). When the trend volume is included in the translation (Fig. 15, left column), the already narrow beach begins shrinking immediately, mirroring the rate of shoreline recession (Fig. 15b-c). After only 20-years of trend erosion, the bed level at the base of the wall passes below mean sea-level (Fig. 15b,c). At this stage, the large variability due to rotation would result in an ephemeral beach, reappearing when easterly events force southward transport. After 30years of trend change and $20 \mathrm{~cm}$ of SLR, the seabed at the base of the wall exceeds the manually set limit of $-2 \mathrm{~m}$ below the future mean sea-level (MLWS), and erosion ceases. Thus by 2050 (Fig. 15c), the beach is predicted to be extinct. By contrast, when only SLR is applied (zero trend, Fig. 15d-f), the beach width is more gradually depleted, but the beach width still reaches zero at the end of the 100year period (Fig. 15f). 

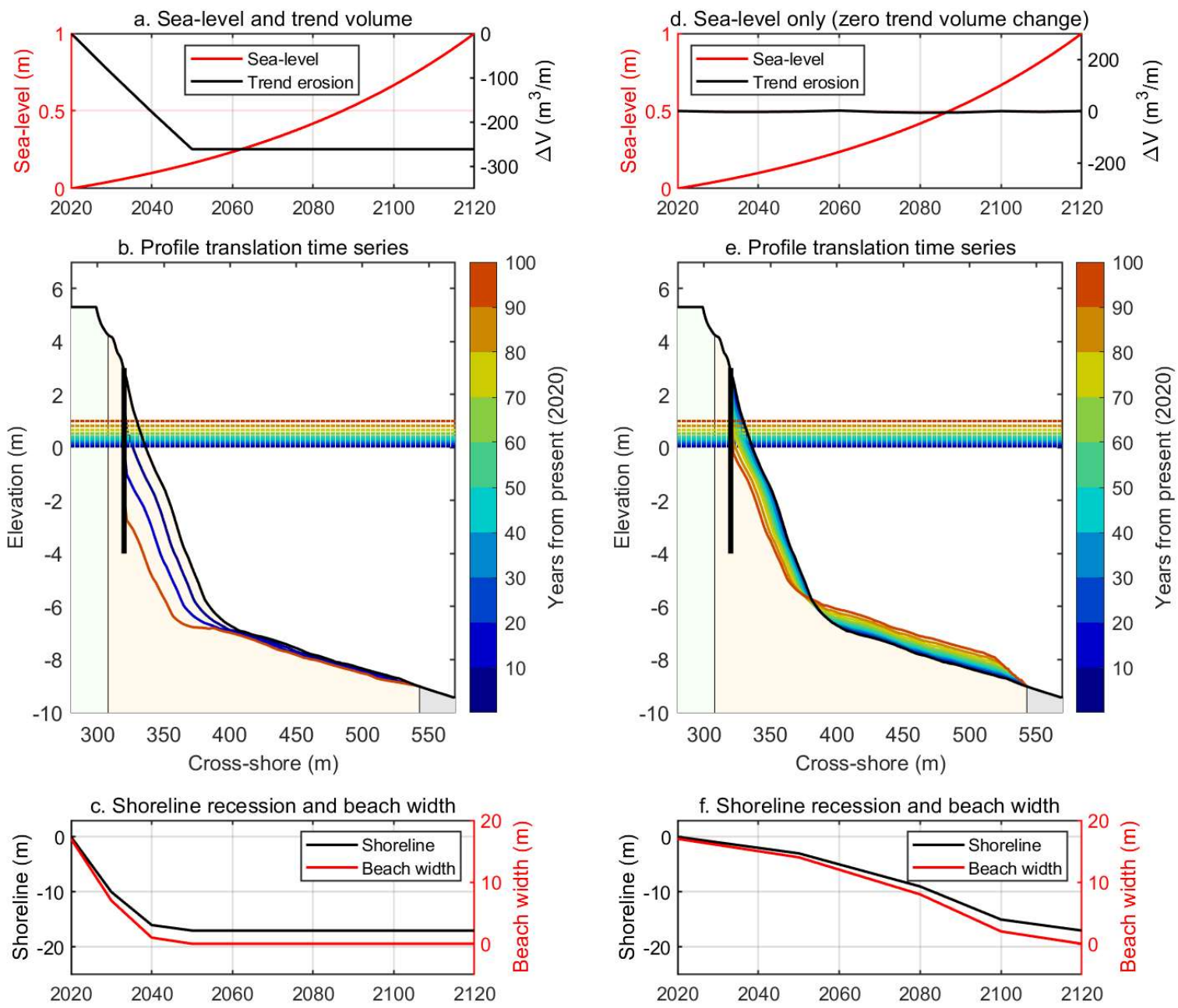

Figure 15. Example profile translation time series for 1-m SLR over 100-years, with trend volume change included (-0.7 $\mathrm{m} / \mathrm{yr}$, left column) and zero trend change (right column), showing shoreline recession and beach 'extinction'. This is a heavily defended profile at Torcross (P0, Fig 14), where sheet-piling (vertical bold black line in $\mathrm{b}$ and e) fronts cemented rock armour, backed by a promenade.

\subsection{Start Bay sediment budget and shoreline recession summary}

A present-day sediment budget was predicted for Start Bay (Fig. 16, top). The budget was calculated by first using the translation model to determine annual rates of volume change, based on the input rates of shoreline change in Table 2 . Note this assumes that the trend rates from 1985-2020 will persist until 2120. Error bars represent the upper/lower uncertainty limits in Table 2. Volume change at each profile was multiplied by the distance alongshore represented by each profile. To maintain simplicity and brevity, the uncertainty introduced by using widely spaced profiles to represent alongshore variable morphology was not accounted for in this instance (see [48] for a more detailed approach). Flux rates $\left(Q ; \mathrm{m}^{3} / \mathrm{yr}\right)$ are the alongshore integral of the volume changes at each profile, with positive values indicating northward transport. The budget indicates a northward flux, peaking within a range 
of 50,000 to $120,000 \mathrm{~m}^{3} / \mathrm{yr}$ at $\mathrm{P} 14$. Despite the simplicity of this approach, the predicted flux rate approaches zero at either end of the embayment (within uncertainty bounds), consistent with the understanding that the Start Bay longshore sediment budget is closed to north and south [47]. This implies that the current rate of shoreline translation in Start Bay (with negligible sea-level rise) may be wholly attributed to longshore transport fluxes, with limited overwash and rollback occurring, at least as a first-pass estimate.

The second panel of Figure 16 displays a comparison of the SLR-only (no trend) forced shoreline recession predicted by ShoreTrans, against predictions using the Bruun-rule. Here, recession rates are generally $10-30 \%$ greater along most of the bay. This is due to rollover of the barrier, which requires onshore transport, thereby increases recession rates (Eq. 3; [9]). This is effect is greatest ( $>30 \%$ increase in recession) where the barrier is narrow and the back-barrier drops down to a lagoon (e.g., P01, P10). Comparatively, onshore transport is reduced where the barrier backs on to a cliff (e.g., P18) and the model predicted shoreline recession will approach the Bruun predicted rate.
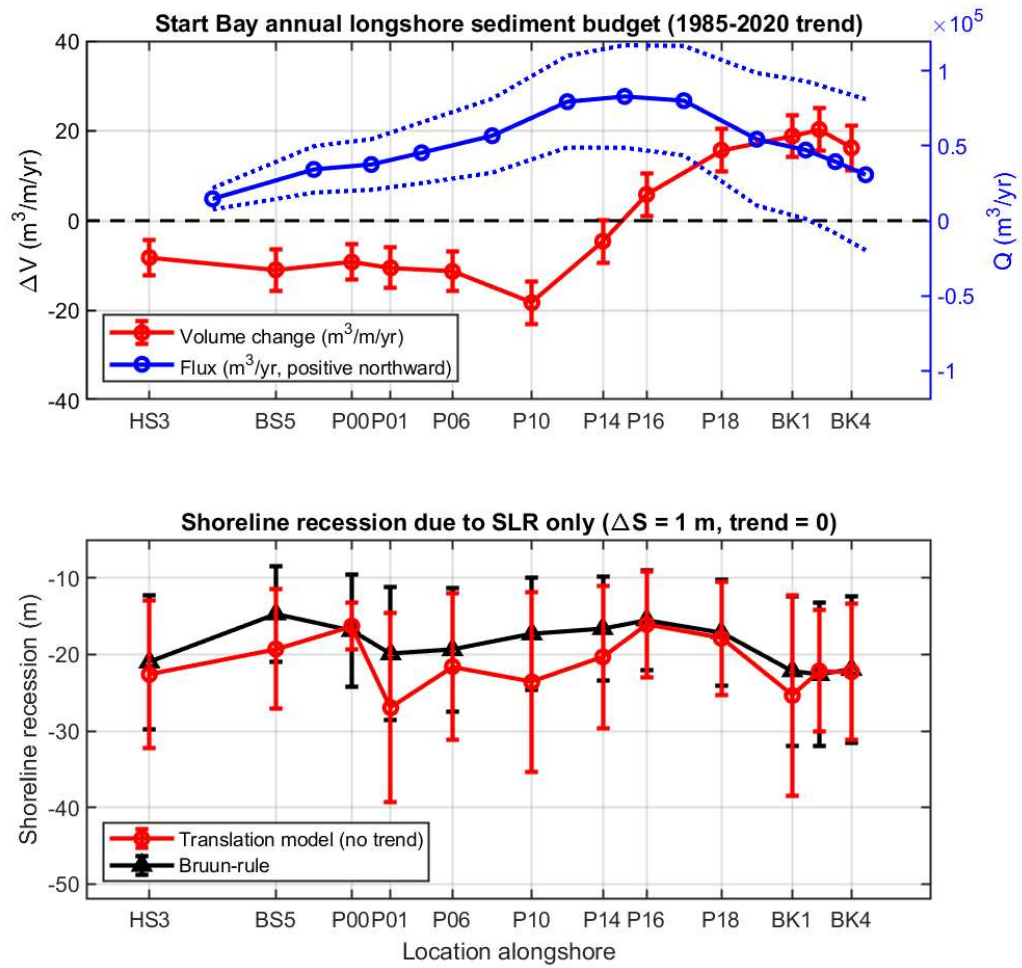

Figure 16. STB full bay sediment budget. (Top) Translation model predicted volume changes over the period 1985 - 2020. (Bottom) Translation model predicted recession for the SLR component, compared against Bruunrule (Eq. 1) estimate. 


\section{Discussion}

\subsection{Summary of site applications}

The outcomes of the application of ShoreTrans to Perranporth (Section 3) and Start Bay (Section 4) are briefly summarised in Table 3, comparing the sites by the factors that contribute to short and longterm variations in shoreline position. The primary forcing controls on shoreline position at Perranporth are cross-shore variability and SLR, both contributing up to $50 \mathrm{~m}$ to shoreline change. By contrast, for Start Bay the dominant effect is the long-term trend in longshore flux towards the north of the bay. Note that we have assumed the trend from 1985-2020 will continue for the next 100 years, which may not be the case if long-term climatic variations impact on wave direction [60]. For Start Bay, SLR is a secondary factor, contributing less than a third to the recession forced by the long-term trend in longshore sediment flux. Short-term alongshore variability at Start Bay is an important secondary factor, but only near headlands (Fig. 14, top). Additionally, it is noted that short-term storm erosion could not be modelled at Start Bay as gravel beach storm erosion is not supported by the model; however, this process may be of secondary importance for some profiles $[48,61,62]$.

There is a high degree of variability both between and within sites, demonstrating the importance of applying a site-specific and profile specific method such as ShoreTrans when predicting shoreface evolution. Both the application sites are macrotidal and not necessarily indicative of other beach types; therefore, a future application to microtidal beaches (e.g., Narrabeen, Australia [63]) would be of benefit.

Table 3. Summary of predicted shoreline impacts for Perranporth and Start Bay of 1-m SLR over 100years, comparing long-term trend and short-term variability.

\begin{tabular}{|c|c|c|c|}
\hline Time-scale & Process & Perranporth & Start Bay \\
\hline \multirow{2}{*}{$\begin{array}{l}\text { Long-term (multi- } \\
\text { decadal) }\end{array}$} & SLR & $\begin{array}{c}\text { Primary } \\
\text { (30 to } 50 \mathrm{~m} \text { recession) }\end{array}$ & $\begin{array}{c}\text { Secondary } \\
\text { (20 to } 30 \mathrm{~m} \text { recession) }\end{array}$ \\
\hline & $\begin{array}{l}\text { Trend inputs/outputs to } \\
\text { active profile }\end{array}$ & $\begin{array}{c}\text { Secondary, but with high } \\
\text { uncertainty (-10 to }+30 \mathrm{~m} \text { to } \\
\text { shoreline position) }\end{array}$ & $\begin{array}{c}\text { Primary } \\
\text { (>100 m shoreline recession at } \\
\text { south and progradation to north) }\end{array}$ \\
\hline \multirow{2}{*}{$\begin{array}{l}\text { Short-term variability } \\
\text { (event scale to } \\
<10 \text { years) }\end{array}$} & $\begin{array}{c}\text { Cross-shore } \\
\text { (storm erosion) }\end{array}$ & $\begin{array}{c}\text { Primary } \\
\text { (up to } 50 \mathrm{~m} \text { shoreline variation) }\end{array}$ & $\begin{array}{c}\text { (Not modelled, } \\
\text { may be important for some } \\
\text { profiles) }\end{array}$ \\
\hline & $\begin{array}{l}\text { Longshore } \\
\text { (rotation) }\end{array}$ & $\begin{array}{l}\text { (Not modelled, } \\
\text { assumed minor) }\end{array}$ & $\begin{array}{l}\text { Secondary near headlands } \\
\qquad(+/-30 \mathrm{~m}) \text {. } \\
\text { Minor at centre of bays. }\end{array}$ \\
\hline
\end{tabular}

The relative contribution of processes impacting shoreline position are classed as primary (red), secondary (orange) and minor (green). 


\subsection{A conceptual approach to shoreface change}

We now expand from site-specific applications to a generalised, idealised, conceptual model (Fig. 17). This approach allows for a broader understanding of how shoreface change is sensitive to SLR and other input variables, which will facilitate further contextualisation of our results with the literature. A reference case is selected (Fig. 17-top, \#4 'Small dune, encroach'), using a power-law profile (Eq. 8; $A=0.25, m=0.67)$, with a 50-m wide berm, a 6-m high dune crest, and the dune toe at $z=3 \mathrm{~m}$. Shoreline recession is compared against a range of profile shapes (varying barrier/dune height, shoreface slope) and translation types (rollover to encroachment). The impact of sediment budget on relative rates of shoreline recession (Fig. 17-middle) and the impact of walls (or hard-rock cliffs) on relative beach width (Fig. 17-bottom) are also included. For all scenarios, a single representative SLR scenario of 1-m over 100-years is simulated, which is approximately equivalent to extrapolating the IPCC high-emissions scenario RCP8.5 to 2120.

Varying translation type (Fig. 17-top, vertical axis) leads to recession rates being maximised (1.5 times the reference case) for 'rollover and keep up', where the barrier translates onshore through overwash and the crest height increase will be equal to SLR (Fig. 17, Profile \#1). Here, sediment flux is directed near-exclusively onshore (red line in bottom sub-panels shows onshore-offshore flux rates), consistent with the generalised Bruun-rule (Eq. 3). Recession rates are reduced if 'encroachment' is assumed (Fig. 17-top, horizontal axis), with all sediment flux directed offshore, as per the standard Bruun-rule (Eq. 2). Increasing dune height (Fig. 17-top, \#5) results in additional supply for offshore transport for every horizontal metre of dune erosion, and therefore reduces recession in encroachment mode. Similarly, a steeper shoreface on a concave-up profile (Fig. 17-top, \#6; $A=0.3$ in Eq. 8) reduces the new accommodation space generated for each incremental increase in sea level, also reducing recession. 


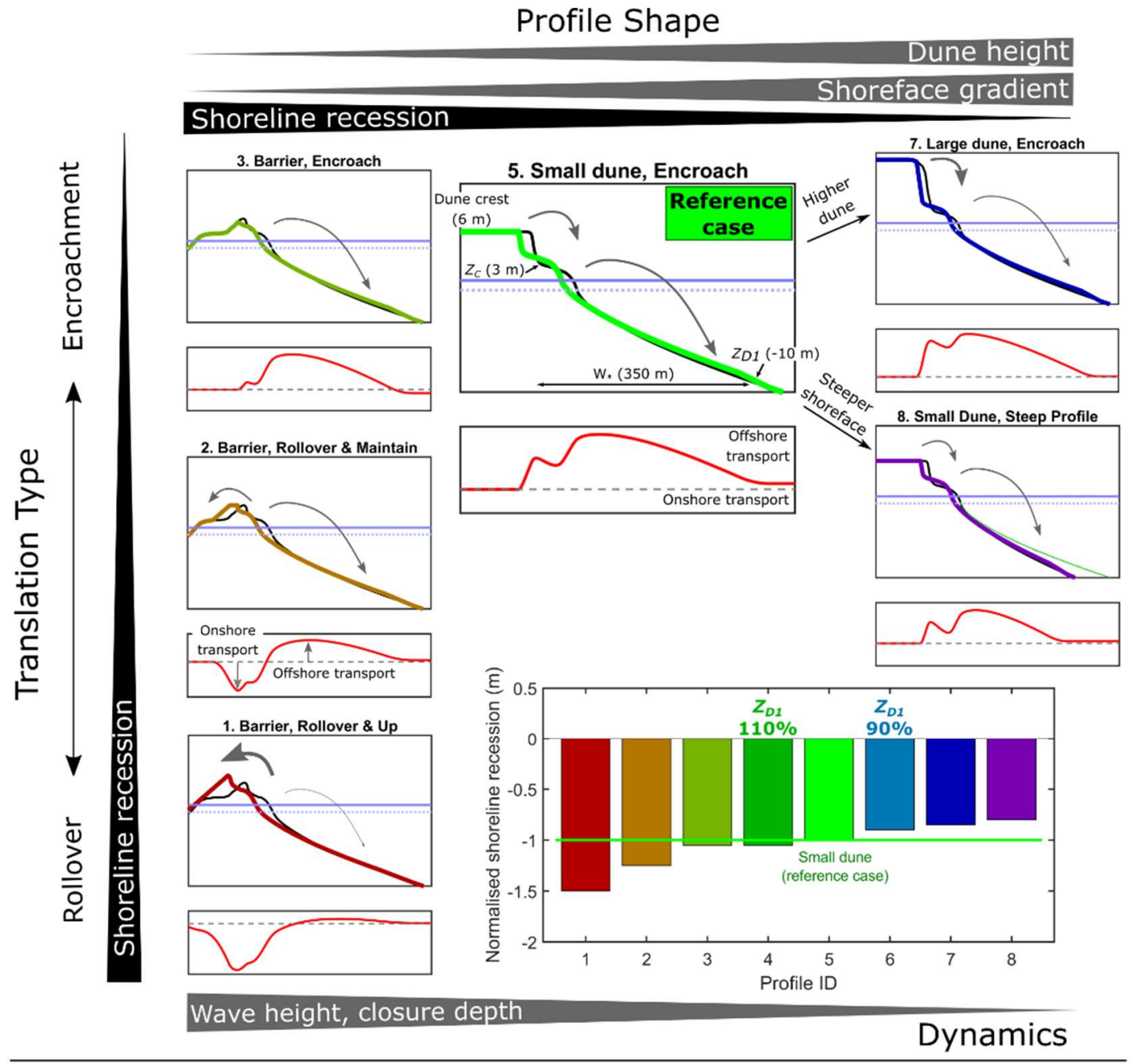

Sediment loss $\stackrel{\text { Sediment Budget }}{\text { Shoreline recession }} \underset{\text { Sediment gain }}{\longrightarrow}$

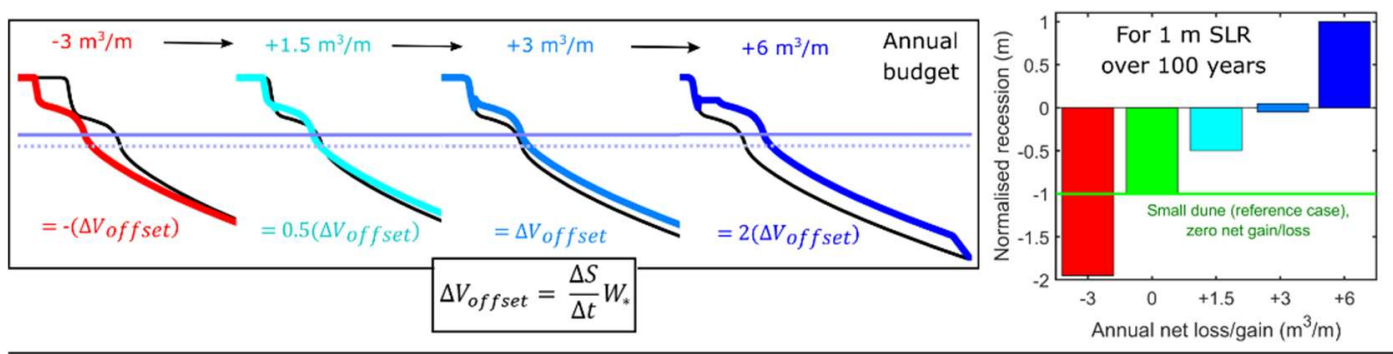

$$
\text { Onshore } \longleftrightarrow \stackrel{\text { Translation Restriction }}{\text { (Wall or cliff location) }} \longrightarrow \text { Offshore }
$$

\section{Beach width}

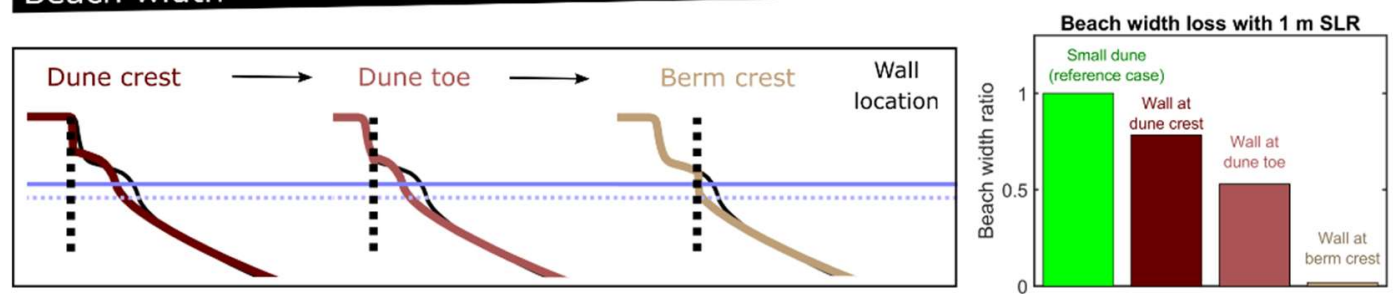


Figure 17 (previous page). Conceptual model of profile translation. A simulation of 1-m SLR over 100years has been applied to all profiles. (Top) Recession rates for a range of translation types and profile shapes. The reference profile (\#5, top panel) is based on a power-law profile below MSL (Eq. $8 ; A=0.25, m=0.67$ ), with a $50 \mathrm{~m}$ wide berm, upper depth of closure at $z=-10$, dune toe at $z=3$ and dune crest at $z=6$. For each profile (\#1-8) the top sub-panel shows the initial and final profile, the bottom sub-panel (red line) indicates relative rates of onshore-offshore sediment flux. Profile \#4 and \#6 on the upper bar plot represent increases or decreases in depth of closure. Arrows indicate direction of sediment transport. (Middle) Recession rates for a range of sediment loss/gain scenarios, relative to the reference case. (Bottom) Beach width loss for a range of wall/cliff positions, relative to the reference case.

For the reference case profile (Fig. 17), with an active profile width of $W_{*}=300 \mathrm{~m}$, sediment inputs on the order $3 \mathrm{~m}^{3} / \mathrm{m} / \mathrm{yr}$ are sufficient to counteract the predicted impact of SLR (Fig. 17-middle row). The inputs in this instance can be any cross- or longshore inputs to the active profile, including longshore transport gradients, onshore transport from lower shoreface, headland bypassing, nourishment or estuarine exchange. Calculation of sediment input required to offset SLR for an idealised profile is straightforward. Beginning with the approach of [3], but expanding the term used for gradual onshore transport from below the upper depth of closure to all sources of volume change to the active profile, the change in shoreline position $(\Delta X)$ over a given time period $(\Delta t)$ is:

$$
\frac{\Delta X}{\Delta t}=-\frac{\Delta S}{\Delta t}\left(\frac{W_{*}}{Z_{D 1}+Z_{C}}\right)+\frac{\Delta V}{\Delta t} \frac{1}{Z_{D 1}+Z_{C}}
$$

The first term on the right of Eq. 9 is the Bruun-rule expressed as a rate, i.e., the rate of SLR divided by the profile gradient ( $\Delta S$ is change is sea-level, $W_{*}$ is active profile width, $Z_{D 1}$ is the depth of closure, $Z_{C}$ is the dune toe / barrier crest), the second term on the right is a catch-all term for volume change to the active profile $\left(\Delta V, \mathrm{~m}^{3} / \mathrm{m}\right)$ distributed over the profile height. This can be solved for the rate of $\Delta V$ required to offset $\mathrm{SLR}$, such that $\frac{\Delta X}{\Delta t}=0$ :

$$
\Delta V_{\text {offset }}\left(\mathrm{m}^{3} / \mathrm{m} / \mathrm{yr}\right)=\frac{\Delta S}{\Delta t} W_{*}
$$

Assuming a rate of SLR of $\Delta S / \Delta t=0.01 \mathrm{~m} / \mathrm{yr}$ and Bruun-type translation (encroachment), a wide dissipative shoreface like Perranporth $\left(W_{*} \approx 1000 \mathrm{~m}\right)$ requires $O(10 \mathrm{~m} / \mathrm{m} / \mathrm{yr})$ to offset $\mathrm{SLR}$ translation effects, while a steeper shoreface like Start Bay (or the reference case in Fig. $17 ; W_{*} \approx$ $300 \mathrm{~m})$ requires $O\left(3 \mathrm{~m}^{3} / \mathrm{m} / \mathrm{yr}\right)$ to offset SLR effects. For real profiles, the net change in volume must 
also account for onshore transport from the active profile [40] to the dune (use 'encroachment mode' plus 'dune accretion') or back barrier (use 'rollover' mode).

Beach width changes are shown to be a function of wall/cliff position (Fig. 17-bottom row), when other inputs are fixed. For the given idealised profile and SLR scenario, a buried wall or cliff located at the initial dune crest will force a beach width reduction of $20 \%$. A wall at the dune toe will result in a $50 \%$ beach reduction, while a wall placed at the berm crest will cause the beach to be entirely eroded. Shoreline recession is also impacted by the presence of a seawall (not shown); however, the result is non-linear and can be misleading. A more seaward wall will exacerbate shoreline recession due to the 'wall-demand' effect [28]; however, if the wall is sufficiently far offshore, the beach will be lost entirely, but the shoreline will remain fixed (cf., Figs. 11, 15).

The conceptual approach is extended to short-term (event scale) cross-shore variability induced by storm erosion (Fig. 18), which is added to the reference case for 1-m SLR (Fig. 17), to indicate the maximum extent of short-term erosion. This allows for an understanding of how the magnitude of SLR translation (long-term trend) compares to the amplitude of the short-term erosion-accretion envelope. Using the generalisation of the [14] approach (Section 2.4, Method 1), a range of storm demand volumes are added to the reference case. In this instance, removal of the berm $\left(-60 \mathrm{~m}^{3} / \mathrm{m}\right.$ in Fig. 18) results in an approximate doubling of shoreline recession (Fig. 18, top right), with small increases in shoreline recession for higher erosion values. Recession at the dune toe (Fig. 18, bottom right) increases rapidly for higher storm demand, with more than 2.5 times the dune recession for 200 $\mathrm{m}^{3} / \mathrm{m}$ of storm erosion volume. For this case, short-term variability may be of a magnitude equal to or greater than SLR translation effects projected for the next century, if storm demand volumes are large. 

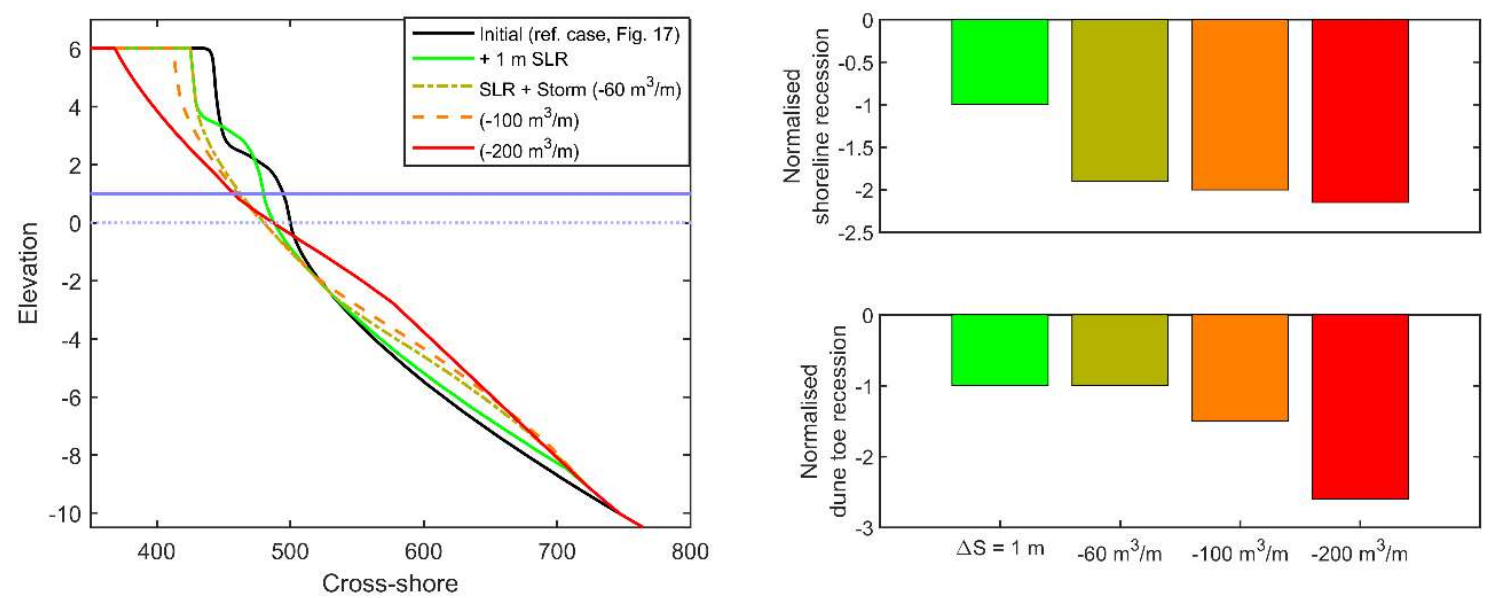

Figure 18. Storm demand volume added to sea-level rise $(\Delta S=1 \mathrm{~m})$, the reference case is as per Fig. 17 (green in all panels). Varying levels of storm demand impact are shown as profiles (left), with normalised shoreline recession (top right) and dune toe recession (bottom right). The $-60 \mathrm{~m}^{3} / \mathrm{m}$ demand equates to complete removal of the berm with zero dune erosion. Storm demand volume is calculated above MSL after SLR is accounted for (solid blue line in left panel). The dune toe is 3-m above MSL.

\subsection{Model limitations and future development Translation rules}

The three ShoreTrans options for barrier translation ('rollback and keep up with SLR', 'rollback and maintain initial height' and 'encroachment') are crude but are suitable for a first-pass assessment of translation distances under various scenarios. Future developments could allow for shape of the barrier to be maintained during translation and/or for a variable amount barrier height growth relative to SLR.

Barrier retreat is currently assumed to be zero in the absence of long-term SLR and/or changes to total profile volume (e.g., due to longshore transport gradients). In reality, low barriers can rollover during high wave and temporary high water level events, such as during hurricanes (e.g., [38]). An option to include a rate of non-SLR related barrier translation could be included in a future iteration.

Additionally, no option is available to allow for passive inundation under SLR (i.e., no raising or translating the profile onshore). Including a 'bath tub' option could be used a benchmark for maximum potential recession rates, and may also allow for even longer term (millennial) estimates of coastal translation, where coastal change rates are predicted to become de-correlated from the active shoreface gradient, and instead become a function of the hinterland gradient [11]. 
This model uses a nodal point $\left(Z_{D 1}\right)$ when transferring sediment from the lower- to upper shoreface. [25] suggests this is unlikely to be an issue at the timeframes considered in this study ( $<100$ years). However, a more gradational approach that accounts for relaxation time and dis-equilibrium (e.g., [25], uses an upper-, middle- and lower shoreface), may be required to allow for reshaping of the profile over longer time frames. Similarly, the reshaping of the active profile to simulate storm erosion (Section 2.4), is designed purely to achieve the necessary volume change at the top of the active profile and at the face of the dune. No effort has been made to accurately represent bar morphology, but relevant methods could be applied (e.g., shape functions; $[64,65]$ ) to provide more realistic predictions of changes to the lower active profile.

\section{Sea-walls and cliffs}

Distribution of displaced 'wall-demand' is unknown in terms of cross-shore extent. A default setting of a triangular distribution across the first third of the profile is used, based on the qualitative conceptual diagram in [28]. Large rates of erosion can lead to potentially unrealistic scour at the base of the wall (Fig. 14). Further observations and morphodynamic modelling are required to improve this component.

\section{Soft-rocks and fine sediments}

ShoreTrans is limited to dealing with unconsolidated sediments or non-erodible walls and substrates. This may be a reasonable assumption for hard-rock cliffs, such as those at Perranporth, where clifferosion rates are negligible over $O(100$ year) timescales. For soft-rock cliffs and semi-consolidated sediments (e.g., $[29,66,67])$, rapid erosion rates can occur, providing a source of sediment that may partially offset recession [11].

For soft-cliff erosion and deep onshore transport, the disturbed sediment may contain a portion of fine-grained sediment that remains suspended in the water column and is carried away from the active profile $[11,15]$. This was not a relevant process in the applications presented here but should be included in a future iteration of the model.

\subsection{Implications for future investigations of shoreline change}

A primary contribution of this work is to provide a simple means of predicting a translated surveyed (non-parameterised) 2D-profile that accounts for complexities and irregularities such as walls, rocks and varying barrier shapes. This can then be used to resolve issues over use of a particular translation formula (e.g., Standard Bruun-encroachment vs. Modified Bruun-rollover), and can further be used to test assumptions and the relative importance of various input factors (e.g., dune height and shape), 
as well as the dominant control on shoreline change (SLR effects, cross-shore variability or long-term trends). The model is well-suited to a future investigation of how variation/uncertainty in inputs contribute to variation in predicted recession rates, both at shoreline and the dune toe, and could be included in existing one-line cross-shore/longshore modelling approaches [5,21].

Additionally, we seek to add clarity to the debate on whether beaches are in danger of becoming "extinct" under a given level of sea-level rise (e.g., $[6,68])$. The issue here is not simply the application of the Bruun-rule; our work suggests that Bruun is a good first-pass estimate (Figs. 12,16,17) provided trend rates of shoreline change, incorporating all aspects of sediment budget, are accounted for. This is consistent with other investigations (Dean and Houston [3], provide a good summary). The key factor often omitted when predicting coastal evolution is onshore accommodation space, i.e., can the barrier translate onshore by eroding a dune or rolling back a barrier, or will this translation be cut-off by a seawall or hard-rock cliff? The key statistic here is beach width, not shoreline recession. Under the assumption that the active profile is able to translate much faster than sea-level rise, narrow beaches backed by seawalls or cliffs are at imminent risk (e.g., Torcross, Fig. 15), wider beaches backed by cliffs or walls will begin to lose beach width under higher rates of sea-level rise (e.g., mid to north Perranporth, Figs. 10-12; Manly, [10]), while dune-backed beaches are unlikely to lose any beach width (south Perranporth, Fig. 10). For beaches backed by infrastructure, such as where houses are built within the active profile (e.g., Narrabeen, Australia [42]), there is risk of losing beach width if the infrastructure is defended ("Hold the line" policy in the UK [39]), but the beach will survive if infrastructure is abandoned ("Managed retreat"), or alternatively if the beach is sufficiently nourished (e.g., [3]). Accordingly, the next report on the future of the world's beaches should focus on beach width, as well as shoreline recession, and the methods described here provide a means with which to address this question of vital public interest. 


\section{Conclusions}

A simple coastal translation model (ShoreTrans) was introduced, capable of predicting future coastal change for a wide range of profile types. The model can incorporate dune erosion, barrier rollover, seawalls and rocky substrates, exchange with the lower shoreface, alongshore redistribution of dune erosion within embayments as well as other inputs and outputs to the sediment budget, e.g., longshore transport. The model also features probabilistic uncertainty and estimates of short-term cross-shore and alongshore variability. A novel aspect of the model is the use of the full cross-shore profile, as opposed to a parameterisation, making it well suited to examining the impact of unusual features such as perched dunes and complex defended profiles.

The translation model was applied to two extensively studied macrotidal sites: Perranporth and Start Bay, in southwest UK. When compared to the standard Bruun-rule approach, the translation model predicted reduced recession rates for dune-backed profiles, increased recession rates for sea-wall and cliff-backed profiles, as well as increased recession for lagoon-backed barriers, where rollover is predicted.

In contrast to previous methods, ShoreTrans provides a prediction of how beach width will change due to sea-level rise. In this regard, narrow beaches $(<50 \mathrm{~m})$ backed by sea-walls are most likely to become extinct given 1-m of sea-level rise, wider beaches backed by cliffs or walls will see moderate reductions (10-70\% loss of beach width), while dune backed beaches and barriers that effectively rollback with sea-level rise are unlikely to lose any beach width. The concept of reduced beach width is critical when addressing future impacts on global shorelines, and this simple model offers coastal researchers a quick and easy means to make that assessment.

\section{Acknowledgements}

This work was funded by a NERC Special Highlights Grant (NE/M004996/1; BLUE-coast project) and an EPSRC Overseas Travel Grant (EP/T004304/1; Coastal Modelling of Extreme Storms and Sea-level Rise). (The data will be made freely available on PEARL [Plymouth University open data server] and code for ShoreTrans will be made freely available if and when the article is accepted for publication). 


\section{References}

[1] Luijendijk, A., Hagenaars, G., Ranasinghe, R., Baart, F., Donchyts, G., \& Aarninkhof, S. (2018). The state of the world's beaches. Scientific reports, 8(1), 1-11.

[2] Mentaschi, L., Vousdoukas, M. I., Pekel, J. F., Voukouvalas, E., \& Feyen, L. (2018). Global long-term observations of coastal erosion and accretion. Scientific reports, 8(1), 1-11.

[3] Dean, R. G., \& Houston, J. R. (2016). Determining shoreline response to sea level rise. Coastal Engineering, 114, 1-8.

[4] Bruun, P. (1954). Coast erosion and the development of beach profiles (Vol. 44). US Beach Erosion Board.

[5] Vitousek, S., Barnard, P. L., Limber, P., Erikson, L., \& Cole, B. (2017a). A model integrating longshore and cross-shore processes for predicting long-term shoreline response to climate change. Journal of Geophysical Research: Earth Surface, 122(4), 782-806.

[6] Vousdoukas, M. I., Ranasinghe, R., Mentaschi, L., Plomaritis, T. A., Athanasiou, P., Luijendijk, A., \& Feyen, L. (2020). Sandy coastlines under threat of erosion. Nature climate change, 10(3), 260-263.

[7] Vitousek, S., Barnard, P. L., Fletcher, C. H., Frazer, N., Erikson, L., \& Storlazzi, C. D. (2017b). Doubling of coastal flooding frequency within decades due to sea-level rise. Scientific reports, 7(1), 1-9.

[8] Masselink, G., Scott, T., Poate, T., Russell, P., Davidson, M., \& Conley, D. (2016). The extreme 2013/2014 winter storms: hydrodynamic forcing and coastal response along the southwest coast of England. Earth Surface Processes and Landforms, 41(3), 378391.

[9] Rosati, J. D., Dean, R. G., \& Walton, T. L. (2013). The modified Bruun Rule extended for landward transport. Marine Geology, 340, 71-81.

[10] Cowell, P. J., Thom, B. G., Jones, R. A., Everts, C. H., \& Simanovic, D. (2006). Management of uncertainty in predicting climate-change impacts on beaches. Journal of Coastal Research, 232-245.

[11] Wolinsky, M. A., \& Murray, A. B. (2009). A unifying framework for shoreline migration: 2. Application to wave-dominated coasts. Journal of Geophysical Research: Earth Surface, 114(F1).

[12] Bruun, P. (1962). Sea-level rise as a cause of shore erosion. Journal of the Waterways and Harbors division, 88(1), 117-132.

[13] Bruun, P. (1988). The Bruun rule of erosion by sea-level rise: a discussion on large-scale two-and three-dimensional usages. Journal of Coastal Research, 627-648.

[14] Kriebel, D. L., \& Dean, R. G. (1993). Convolution method for time-dependent beachprofile response. Journal of Waterway, Port, Coastal, and Ocean Engineering, 119(2), 204-226.

[15] Cowell, P. J., Roy, P. S., \& Jones, R. A. (1995). Simulation of large-scale coastal change using a morphological behaviour model. Marine Geology, 126(1-4), 45-61. 
[16] Dean, R. G., \& Maurmeyer, E. M. (1983). Models for beach profile response, Handbook of Coastal Processes and Erosion, Edited by PD Komar.

[17] Cowell, Peter J., Marcel JF Stive, Peter S. Roy, George M. Kaminsky, Maarten C. Buijsman, Bruce G. Thom, and L. Don Wright. "Shoreface sand supply to beaches." In Coastal Engineering 2000, pp. 2495-2508. 2001.

[18] Luijendijk, A. P., de Schipper, M. A., \& Ranasinghe, R. (2019). Morphodynamic acceleration techniques for multi-timescale predictions of complex sandy interventions. Journal of Marine Science and Engineering, 7(3), 78.

[19] Robinet, A., Idier, D., Castelle, B., \& Marieu, V. (2018). A reduced-complexity shoreline change model combining longshore and cross-shore processes: the LX-Shore model. Environmental modelling \& software, 109, 1-16.

[20] Robinet, A., Castelle, B., Idier, D., Harley, M. D., \& Splinter, K. D. (2020). Controls of local geology and cross-shore/longshore processes on embayed beach shoreline variability. Marine Geology, 106118.

[21] Antolínez, J. A., Méndez, F. J., Anderson, D., Ruggiero, P., \& Kaminsky, G. M. (2019). Predicting Climate-Driven Coastlines With a Simple and Efficient Multiscale Model. Journal of Geophysical Research: Earth Surface, 124(6), 1596-1624.

[22] Davidson, M. A., Lewis, R. P., \& Turner, I. L. (2010). Forecasting seasonal to multi-year shoreline change. Coastal Engineering, 57(6), 620-629.

[23] Montaño, J., Coco, G., Antolínez, J. A., Beuzen, T., Bryan, K. R., Cagigal, L., ... \& Idier, D. (2020). Blind testing of shoreline evolution models. Scientific Reports, 10(1), 1-10.

[24] Cowell, P. J., Roy, P. S., \& Jones, R. A. (1992). Shoreface translation model: computer simulation of coastal-sand-body response to sea level rise. Mathematics and computers in simulation, 33(5-6), 603-608.

[25] Stive, M. J., \& De Vriend, H. J. (1995). Modelling shoreface profile evolution. Marine Geology, 126(1-4), 235-248.

[26] Storms, J. E., Weltje, G. J., Van Dijke, J. J., Geel, C. R., \& Kroonenberg, S. B. (2002). Process-response modeling of wave-dominated coastal systems: simulating evolution and stratigraphy on geological timescales. Journal of Sedimentary Research, 72(2), 226-239.

[27] Atkinson, A. L., Baldock, T. E., Birrien, F., Callaghan, D. P., Nielsen, P., Beuzen, T., ... \& Ranasinghe, R. (2018). Laboratory investigation of the Bruun Rule and beach response to sea level rise. Coastal Engineering, 136, 183-202.

[28] Beuzen, T., Turner, I. L., Blenkinsopp, C. E., Atkinson, A., Flocard, F., \& Baldock, T. E. (2018). Physical model study of beach profile evolution by sea level rise in the presence of seawalls. Coastal Engineering, 136, 172-182.

[29] Kinsela, M. A., Morris, B. D., Linklater, M., \& Hanslow, D. J. (2017). Second-pass assessment of potential exposure to shoreline change in New South Wales, Australia, using a sediment compartments framework. Journal of Marine Science and Engineering, 5(4), 61. 
[30] Wainwright, D. J., Ranasinghe, R., Callaghan, D. P., Woodroffe, C. D., Jongejan, R., Dougherty, A. J., ... \& Cowell, P. J. (2015). Moving from deterministic towards probabilistic coastal hazard and risk assessment: Development of a modelling framework and application to Narrabeen Beach, New South Wales, Australia. Coastal engineering, 96, 92-99.

[31] Masetti, R., Fagherazzi, S., \& Montanari, A. (2008). Application of a barrier island translation model to the millennial-scale evolution of Sand Key, Florida. Continental Shelf Research, 28(9), 1116-1126.

[32] Nicholls, R. J., Birkemeier, W. A., \& Lee, G. H. (1998). Evaluation of depth of closure using data from Duck, NC, USA. Marine Geology, 148(3-4), 179-201.

[33] Hallermeier, R.J., 1981. A profile zonation for seasonal sand beaches from wave climate. Coast. Eng. 4 (C), 253-277.

[34] Valiente, N. G., Masselink, G., Scott, T., Conley, D., \& McCarroll, R. J. (2019a). Role of waves and tides on depth of closure and potential for headland bypassing. Marine Geology, 407, 60-75.

[35] Kotvojs, F., \& Cowell, P. J. (1991). Refinement ofthe Dean profile model for equilibrium beach pro-files. Australian Civil Engineering Transactions, 33, 9-15.

[36] Orford, J. D., Carter, R. W. G., Jennings, S. C., \& Hinton, A. C. (1995). Processes and timescales by which a coastal gravel-dominated barrier responds geomorphologically to sea-level rise: Story head barrier, Nova Scotia. Earth Surface Processes and Landforms, 20(1), 21-37.

[37] Plant, N. G., \& Stockdon, H. F. (2012). Probabilistic prediction of barrier-island response to hurricanes. Journal of Geophysical Research: Earth Surface, 117(F3).

[38] Lorenzo-Trueba, J., \& Ashton, A. D. (2014). Rollover, drowning, and discontinuous retreat: Distinct modes of barrier response to sea-level rise arising from a simple morphodynamic model. Journal of Geophysical Research: Earth Surface, 119(4), 779801.

[39] Masselink, G., Russell, P., Rennie, A., Brooks, S., \& Spencer, T. (2020). Impacts of climate change on coastal geomorphology and coastal erosion relevant to the coastal and marine environment around the UK. MCCIP Science Review 2020, 158-189.

[40] Stive, M. J. (2004). How important is global warming for coastal erosion?. Climatic Change, 64(1-2), 27.

[41] Sallenger Jr, A. H. (2000). Storm impact scale for barrier islands. Journal of Coastal Research, 890-895.

[42] Beuzen, T., Harley, M. D., Splinter, K. D., \& Turner, I. L. (2019). Controls of variability in berm and dune storm erosion. Journal of Geophysical Research: Earth Surface, 124(11), 2647-2665.

[43] Dean, R. G. (1977). Equilibrium beach profiles: US Atlantic and Gulf coasts. Department of Civil Engineering and College of Marine Studies, University of Delaware. 
[44] Loureiro, C., Ferreira, Ó., \& Cooper, J. A. G. (2012). Extreme erosion on high-energy embayed beaches: influence of megarips and storm grouping. Geomorphology, 139, 155-171.

[45] McCarroll, R. J., Brander, R. W., Turner, I. L., \& Van Leeuwen, B. (2016). Shoreface storm morphodynamics and mega-rip evolution at an embayed beach: Bondi Beach, NSW, Australia. Continental Shelf Research, 116, 74-88.

[46] Harley, M. D., Turner, I. L., Short, A. D., \& Ranasinghe, R. (2011). A reevaluation of coastal embayment rotation: The dominance of cross-shore versus alongshore sediment transport processes, Collaroy-Narrabeen Beach, southeast Australia. Journal of Geophysical Research: Earth Surface, 116(F4).

[47] Wiggins, M., Scott, T., Masselink, G., Russell, P., \& McCarroll, R. J. (2019). Coastal embayment rotation: Response to extreme events and climate control, using full embayment surveys. Geomorphology, 327, 385-403.

[48] McCarroll, R. J., Masselink, G., Wiggins, M., Scott, T., Billson, O., Conley, D. C., \& Valiente, N. G. (2019a). High-efficiency gravel longshore sediment transport and headland bypassing over an extreme wave event. Earth Surface Processes and Landforms, 44(13), 2720-2727.

[49] Valiente, N. G., McCarroll, R. J., Masselink, G., Scott, T., \& Wiggins, M. (2019b). Multiannual embayment sediment dynamics involving headland bypassing and sediment exchange across the depth of closure. Geomorphology, 343, 48-64.

[50] Le Cozannet, G., Oliveros, C., Castelle, B., Garcin, M., Idier, D., Pedreros, R., \& Rohmer, J. (2016). Uncertainties in sandy shorelines evolution under the Bruun rule assumption. Frontiers in Marine Science, 3, 49.

[51] Poate, T., Masselink, G., Russell, P., \& Austin, M. (2014). Morphodynamic variability of high-energy macrotidal beaches, Cornwall, UK. Marine Geology, 350, 97-111.

[52] Stokes, C., Davidson, M., \& Russell, P. (2015). Observation and prediction of threedimensional morphology at a high-energy macrotidal beach. Geomorphology, 243, 113.

[53] Scott, T., Masselink, G., O'Hare, T., Saulter, A., Poate, T., Russell, P., ... \& Conley, D. (2016). The extreme 2013/2014 winter storms: Beach recovery along the southwest coast of England. Marine Geology, 382, 224-241.

[54] McCarroll, R. J., Masselink, G., Valiente, N. G., Scott, T., King, E. V., \& Conley, D. (2018). Wave and tidal controls on embayment circulation and headland bypassing for an exposed, macrotidal site. Journal of Marine Science and Engineering, 6(3), 94.

[55] Valiente, N. G., Masselink, G., McCarroll, R. J., Scott, T., Conley, D.C., King, E.V. (under review). Nearshore sediment pathways and potential sediment budgets in embayed settings over a multi-annual timescale. Marine Geology.

[56] Vos, K., Splinter, K. D., Harley, M. D., Simmons, J. A., \& Turner, I. L. (2019). CoastSat: A Google Earth Engine-enabled Python toolkit to extract shorelines from publicly available satellite imagery. Environmental Modelling \& Software, 122, 104528. 
[57] Hails, J. R. (1975). Submarine geology, sediment distribution and Quaternary history of Start Bay, Devon. Journal of the Geological Society, 131(1), 1-5.

[58] McCarroll, R. J., Masselink, G., Valiente, N. G., Wiggins, M., Scott, T., Conley, D. C., \& King, E. V. (2020). Impact of a headland-associated sandbank on shoreline dynamics. Geomorphology, 355, 107065.

[59] Wiggins, M., Scott, T., Masselink, G., Russell, P., Castelle, B., \& Dodet, G. (2017). The role of multi-decadal climate variability in controlling coastal dynamics: reinterpretation of the 'lost village of Hallsands'. In Coastal Dynamics (pp. 96-107).

[60] Scott, T., Masselink, G., McCarroll., R.J., Castelle, B., Dodet, G., Saulter, A., Scaife, A.A. \& Dunstone, N.J. (under review). Atmospheric controls and long range predictability of directional waves in the United Kingdom \& Ireland. Earth's Future.

[61] de Alegria-Arzaburu, A. R., \& Masselink, G. (2010). Storm response and beach rotation on a gravel beach, Slapton Sands, UK. Marine Geology, 278(1-4), 77-99.

[62] McCarroll, R.J., Masselink, G., Wiggins, M., Scott, T., Billson, O., Conley, D. (2019b). Gravel beach cross- and alongshore response to an extreme event: Beach length and headland proximity controls.

[63] Turner, I. L., Harley, M. D., Short, A. D., Simmons, J. A., Bracs, M. A., Phillips, M. S., \& Splinter, K. D. (2016). A multi-decade dataset of monthly beach profile surveys and inshore wave forcing at Narrabeen, Australia. Scientific data, 3(1), 1-13.

[64] Masselink, G. (2004). Formation and evolution of multiple intertidal bars on macrotidal beaches: application of a morphodynamic model. Coastal Engineering, 51(8-9), 713730.

[65] Marino-Tapia, I. J., Russell, P. E., O'Hare, T. J., Davidson, M. A., \& Huntley, D. A. (2007). Cross-shore sediment transport on natural beaches and its relation to sandbar migration patterns: 1 . Field observations and derivation of a transport parameterization. Journal of Geophysical Research: Oceans, 112(C3).

[66] Walkden, M. J., \& Hall, J. W. (2011). A mesoscale predictive model of the evolution and management of a soft-rock coast. Journal of Coastal research, 27(3), 529-543.

[67] Brooks, S.M. and Spencer, T.S. (2014) Importance of decadal scale variability in shoreline response: examples from soft rock cliffs, East Anglian coast, UK. Journal of Coastal Conservation: Planning and Management 18, 581-593. (DOI: 10.1007/s11852013-0279-7).

[68] Vitousek, S., Barnard, P. L., \& Limber, P. (2017c). Can beaches survive climate change? Journal of Geophysical Research: Earth Surface, 122(4), 1060-1067. 